\title{
Fuzzy-logic-based support tools for initial screening of manufacturing reshoring decisions
}

Fuzzy-logicbased support tools

Per Hilletofth

\author{
Department of Industrial Engineering and Management, University of Gävle, \\ Gävle, Sweden and \\ Department of Industrial Engineering and Management, Jönköping University, \\ Jönköping, Sweden \\ Movin Sequeira \\ Industrial Product, Production Development and Design, Jönköping University, \\ Jönköping, Sweden, and \\ Wendy Tate \\ Department of Supply Chain Management, College of Business Administration, \\ University of Tennessee, Knoxville, Tennessee, USA
}

\begin{abstract}
Purpose - This paper investigates the suitability of fuzzy-logic-based support tools for initial screening of manufacturing reshoring decisions.

Design/methodology/approach - Two fuzzy-logic-based support tools are developed together with experts from a Swedish manufacturing firm. The first uses a complete rule base and the second a reduced rule base. Sixteen inference settings are used in both of the support tools.

Findings - The findings show that fuzzy-logic-based support tools are suitable for initial screening of manufacturing reshoring decisions. The developed support tools are capable of suggesting whether a reshoring decision should be further evaluated or not, based on six primary competitiveness criteria. In contrast to existing literature this research shows that it does not matter whether a complete or reduced rule base is used when it comes to accuracy. The developed support tools perform similarly with no statistically significant differences. However, since the interpretability is much higher when a reduced rule base is used and it require fewer resources to develop, the second tool is more preferable for initial screening purposes.

Research limitations/implications - The developed support tools are implemented at a primary-criteria level and to make them more applicable, they should also include the sub-criteria level. The support tools should also be expanded to not only consider competitiveness criteria, but also other criteria related to availability of resources and strategic orientation of the firm. This requires further research with regard to multi-stage architecture and automatic generation of fuzzy rules in the manufacturing reshoring domain.

Practical implications - The support tools help managers to invest their scarce time on the most promising reshoring projects and to make timely and resilient decisions by taking a holistic perspective on competitiveness. Practitioners are advised to choose the type of support tool based on the available data.

Originality/value - There is a general lack of decision support tools in the manufacturing reshoring domain. This paper addresses the gap by developing fuzzy-logic-based support tools for initial screening of manufacturing reshoring decisions.
\end{abstract}

Keywords Manufacturing reshoring, Decision support, Initial screening, Fuzzy logic

Paper type Research paper

(C) Per Hilletofth, Movin Sequeira and Wendy Tate. Published by Emerald Publishing Limited. This article is published under the Creative Commons Attribution (CC BY 4.0) licence. Anyone may reproduce, distribute, translate and create derivative works of this article (for both commercial and noncommercial purposes), subject to full attribution to the original publication and authors. The full terms of this licence may be seen at http://creativecommons.org/licences/by/4.0/legalcode.

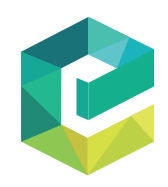

Received 22 May 2020

Revised 5 October 2020

27 November 2020

5 January 2021

Accepted 21 January 2021 
IMDS

121,5

966

\section{Introduction}

Over the last three decades an extensive movement of manufacturing activities from high-cost to low-cost contexts has taken place (Brennan et al., 2015; Ketokivi et al., 2017). This offshoring has been sustained by the idea that there is a compelling advantage in having manufacturing located in low-cost environments. The key motive has been to reduce manufacturing cost, or more precisely labor cost (Vanchan et al., 2018; Gylling et al., 2015). A reduction in production cost was often achieved, but in many cases, it also became clear that the decision had been based on incomplete information (Eriksson et al., 2018). Typically, a total cost-of-ownership view was missing, resulting in many critical criteria not being included in the decision. The decision-making frameworks that were used and the calculations generated were thus rudimentary (Bailey and De Propris, 2014; Stentoft et al., 2015). Another reason that offshoring decisions over time have become less attractive is that the market has evolved, favoring other types of supply chain designs (Hilletofth et al., 2019a). These offshoring failures and market changes have led to an intensified debate about the opposing movement of material and services (reshoring), back to the home country (Arlbjørn and Mikkelsen, 2014; Gray et al., 2013), or to an adjacent country (Panova and Hilletofth, 2017).

Manufacturing reshoring decisions are complex in structure and handling as the number of decision criteria could grow rapidly and make it difficult to find an optimal solution that is resilient over time (Gray et al., 2017; Hartman et al., 2017; Wiesmann et al., 2017). The more prominent groups of criteria to consider in a reshoring decision include quality-related criteria (Johansson and Olhager, 2018), cost-related criteria (Di Mauro et al., 2018), marketrelated criteria (Tate et al., 2014) and strategy-related criteria (Baraldi et al., 2018). The complexity is related to the vast number of criteria that must be considered in the decision, the trade-offs and paradoxes between criteria that must be balanced (Gray et al., 2017; Tate et al., 2014), and the lack of sufficient data on the criteria or uncertainties in available data (Foerstl et al., 2016). A lack of institutional experience further adds to the complexity in reshoring decision-making (Bals et al., 2016; Gray et al., 2017).

The complexity inherent in manufacturing reshoring decisions necessitate decisionsupport tools that can aid firms in making more appropriate reshoring decisions that are resilient over time (Hilletofth et al., 2019a). There is a lack of decision-support tools for evaluation of manufacturing reshoring decisions (Barbieri et al., 2018; Stentoft et al., 2016). Some manually handled decision-making frameworks have been proposed in the literature for complex manufacturing reshoring decisions in a formal and structured manner (e.g. Gylling et al., 2015; Bals et al., 2016; Joubioux and Vanpoucke, 2016). However, these frameworks are mainly theoretical and conceptual and lack both digital and automated decision support capabilities. Therefore, there is a need for more advanced decision-support tools in the manufacturing reshoring domain (Hilletofth et al., 2019b).

Decision-support tools can be created in many ways. The basic requirement is that the tool must be efficient and effective, as well as deliver pertinent, accurate, reliable and interpretable information in order for the decision-maker to make a qualified decision (Hilletofth et al., 2016). Three usual types of decision-support tools include: data-driven tools that analyze large amounts of data to evaluate decisions, model-driven tools that use analytical models to evaluate decisions and knowledge-driven tools that use domain knowledge to evaluate decisions (Power, 2008). The increased interest in artificial intelligence techniques, especially machine learning, is promoting data-driven tools (Sadati et al., 2018). However, in the manufacturing reshoring domain there is usually a lack of sufficient data (Foerstl et al., 2016) and also huge uncertainties in the available data. Most of the available knowledge is typically found in domain experts. Thus, knowledge-driven tools are preferable in this context.

One example of a knowledge-driven support tool is the expert systems (Power, 2008; Nunes and Jannach, 2017). An expert system is an information system that uses knowledge from domain experts to support decision-makers in the decision-making process. This allows 
managers with less expertise to use this knowledge and thus make better decisions (Power, 2008; Leo Kumar, 2019). The role of expert systems is to support human decision-makers rather than replacing them (Power, 2008). When building a rule-based expert system, the knowledge of the domain experts is modelled into a series of rules (heuristics) similar to how human experts would reason and is used in an inference system for problem-solving. Hence, logic is used to make a deductive decision. The expert system is considered as an artificial intelligence technique since a computer is used to support the decision-making process (Liao, 2005; Leo Kumar, 2019).

Various modeling techniques may be used to develop rule-based expert systems. Recently, fuzzy logic has been used to build a rule-based expert system for evaluation of manufacturing reshoring decisions with promising results (Hilletofth et al., 2019b). For several reasons, fuzzy-logic-based tools look appropriate for this decision-making context. First, they provide a means for handling the uncertainty linked to the lack of sufficient data or uncertainties in the available data (Ross, 2017). Second, they provide a means for handling the complexity linked to a vast number of occasionally conflicting criteria that must be considered and balanced in the decision (Shaout and Trivedi, 2013). Third, they provide a means for capturing domain knowledge and expertise on the crucial decision criteria (Morente-Molinera et al., 2017) that can be used to support reasoning with otherwise vague and imprecise information. The limited existing research on fuzzy-logic-based decision-support tools in the manufacturing reshoring domain has so far focused on the development of fuzzy logic concepts suitable for this domain (Hilletofth et al., 2019b). There is a gap in research that focuses on developing decision support tools for specific decision-making situations. For instance, a decision support tool for initial evaluation in the beginning of the decision-making process, a stepwise decision support tool that is used throughout the decision-making process or a decision support tool for complete evaluation in the end of the decision-making process.

The aim of this research is to investigate the suitability of fuzzy-logic-based support tools for initial screening of manufacturing reshoring decisions. To achieve this, two such support tools were developed. A fuzzy-logic-based support tool must be accurate, reliable and interpretable, and with a tradeoff between accuracy and interpretability (Cordón, 2011; Shukla and Tripathi, 2012). The aim could either be to develop a tool distinguished by high accuracy that relies on a large rule base, or high interpretability that relies on a small rule base (Cordón, 2011; Cpałka, 2017; Zhou and Gan, 2008). The interpretability of the tool can be enhanced by reducing the rule base (Mencar and Fanelli, 2008; Casillas et al., 2013). However, a small rule base could create issues with consistency, completeness and redundancy (Duţu et al., 2018; Gacto et al., 2011; Gegov et al., 2017). Hence, it is a major challenge to develop fuzzylogic-based support tools that are accurate, reliable and interpretable. The first developed support tool uses a complete rule base while the second uses a reduced rule base. In both support tools, sixteen fuzzy inference settings are used. The input for the two support tools is thirty decision (or input) scenarios that consist of six decision criteria each. The decision scenarios provide the data needed to assess the suitability of the developed fuzzy-logic-based support tools for initial screening of manufacturing reshoring decisions.

The remainder of the paper is structured as follows. A review of manufacturing reshoring and fuzzy logic is provided in Section 2. The developed fuzzy-logic-based support tools for reshoring are described in Section 3. Thereafter, the results are presented and discussed in Sections 4 and 5 respectively. Finally, the research is concluded in Section 6.

\section{Literature review}

In order to provide a contextual understanding, a review of the existing manufacturing reshoring and fuzzy logic literature is provided further. The reviews are focused on the issues most relevant for this research work.
Fuzzy-logicbased support tools

967 
IMDS

121,5

968

\subsection{Reshoring}

The definition of manufacturing reshoring is starting to reach consensus in the literature (Barbieri et al., 2018). It is fundamentally a location decision (Gray et al., 2013) involving manufacturing activities, as opposed to other types of value chain activities (Barbieri et al., 2018). Some researchers also distinguish between "backshoring" and "nearshoring" (Fratocchi et al., 2014), where the former is about movements back to the home country, and the latter is about movements to a near-to-home country (Ellram et al., 2013). Four types of manufacturing reshoring can be distinguished based on two dimensions. The first dimension is the location decision and the second dimension is the control or governance (make or buy) decision (Gray et al., 2013). It is argued that both these decisions are interconnected (Bals et al., 2016). The different types of manufacturing reshoring include reshoring of inhouse activity, reshoring for outsourcing, reshoring for insourcing and reshoring of outsourced activity. The scope of a reshoring project may differ significantly, ranging from a factory, a production process, a production phase, a product or a component (Baraldi et al., 2018; Gray et al., 2013). The extent of manufacturing reshoring also differs from partial reshoring to complete reshoring, where the former implies a partial closure of the offshore venture (Fratocchi et al., 2014).

The manufacturing reshoring decision-making process may be visualized in various ways and the existing literature include some examples (Bals et al., 2016; Boffelli et al., 2018). In essence, the decision-making process consists of five main steps (Figure 1). In the first step the reshoring project is defined, which consists of determining the reshoring scope (e.g. factory, process, phase, product or component), reshoring extent (partial or complete), and reshoring context (e.g. industry, firm, market and product characteristics). In the second step, performance of the current supply chain setup is evaluated. This step consists of information gathering related to current supply chain performance within the context of the reshoring project (Boffelli et al., 2018). In the third step, possible reshoring scenarios are identified. The reshoring scenarios correspond to the choices that the firm can take with regard to location and control (Gray et al., 2013). In the fourth step, the identified reshoring scenarios are evaluated. In the final step a reshoring scenario is selected, which could even include the choice of staying at the current location. In all steps the firms strategies and boundaries must be considered. The decision-making process is started by so called trigger (or drivers). The triggers, drivers or motives for manufacturing reshoring is one of the most common research topics in this domain (Wiesmann et al., 2017; Barbieri et al., 2018).

Manufacturing reshoring decisions are complex since the number of decision criteria could grow rapidly and make it difficult to find a suitable solution that is resilient over time (Gray et al., 2017; Hartman et al., 2017). The decision factors are all those that influence the reshoring decision and include drivers, enablers and barriers (Wiesmann et al., 2017). Many decision factors have been presented in the literature and are often grouped according to theory-driven frameworks such as Dunning's eclectic paradigm (Dunning, 1980), including cost-seeking, market-seeking, resource-seeking and strategic-asset seeking (Ancarani et al., 2015; Ellram et al., 2013).

Some recent frameworks of factors that influence the reshoring decision have been proposed in the literature. In one such framework, the factors are divided according to the main goal (cost efficiency or perceived value) and the level of analysis (internal or external)

Figure 1.

The manufacturing reshoring decisionmaking process

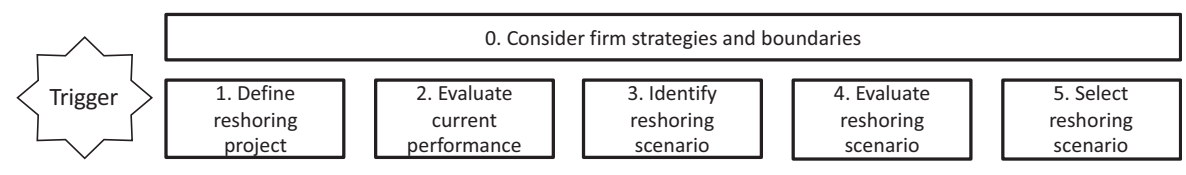

Source(s): Based on Bals et al., 2016; Boffelli et al., 2018 
(Fratocchi et al., 2016). In another framework, the factors are divided into global competitive dynamics, host country, home country, supply chain and firm-specific issues (Wiesmann et al., 2017). Some frameworks group the factors based on competitive priorities, arguing that firms reshore to increase their competitiveness (Benstead et al., 2017; Srai et al., 2016). Recently, attention also has been devoted to grouping the factors as either "managerial mistakes", "strategic shift" and "environmental conditions" so as to separate the factors arising from management mistakes from those arising from the firm's internationalization strategy (Di Mauro et al., 2018) or changes in the environmental conditions (Martinez-Mora and Merino, 2014).

Manufacturing reshoring decisions are not only complex due to the huge number of criteria that must be included in the decision, but also with regard to various trade-offs and paradoxes between the criteria that must be balanced (Gray et al., 2017; Tate et al., 2014). The decision-maker must be aware of, and consider a large number of trade-offs and try accordingly to make the best possible decision (Gray et al., 2017; Tate et al., 2014). The tradeoff analyses are often cost-based, and the decision-maker attempts to achieve the lowest landed cost or the lowest cost of ownership between various locations (Gylling et al., 2015; Hartman et al., 2017).

It has been argued these types of analyses are not sufficient, and research calls for decision tools that can incorporate better heuristics of the criteria that are not easily quantifiable, or cannot be implemented in landed cost or total cost-of-ownership models (Gray et al., 2017; Barbieri et al., 2018). Other reasons for the complexity include a lack of sufficient data on the factors or uncertainties in the available data (Foerstl et al., 2016), as well as a lack of institutional experience (Bals et al., 2016; Gray et al., 2017). The final decision should be delayed in the decision-making process until all relevant criteria have been identified, and appropriate information on the criteria is available (Hartman et al., 2017).

The point has also been made that firms have relied on too limited number of criteria in the decision-making, and that they have discovered critical criteria rather late in the decisionmaking process. It has also been argued that the timing is critical as managers do not want to lose opportunities by evaluating the decision too long (Boffelli et al., 2018). This presents opportunities for initial screening tools helping to both speed up the process and make sure that the relevant criteria are considered.

In order to handle complex manufacturing reshoring decisions in a systematic manner, various decision-making frameworks have been proposed in the literature. One of these frameworks makes use of existing costs models to make a cost-based decision (Gylling et al., 2015). The decision is based on the comparison of a firm's own production cost calculated using a time-driven activity-based costing model, with the sourcing cost calculated using a total landed cost model. Another framework takes off from the fact that the reshoring decision often depends on the benefits and challenges of previous offshoring (Joubioux and Vanpoucke, 2016). First, push factors (discouraging offshoring), pull factors (encouraging reshoring), new risk assessment and benefits of previous offshoring are evaluated. After that, the firm decides either to further offshore the production, maintain the production at the current location or reshore the production to the home country, based on current benefits and challenges of the offshoring venture. These frameworks, however, are predominantly theoretical exercises that lack both digital and automated decision-support capabilities. Thus, there is a need for more advanced decision-support tools for evaluation of manufacturing reshoring decisions (Hilletofth et al., 2019b; Wiesmann et al., 2017).

Even if existing research demands more advanced decision-support tools in the manufacturing reshoring domain, the types of support tools needed are not specified. The complexity in the decision-making process demands different kinds of support tools for different purposes (i.e. decision-making situations). Taking departure from the decision-
Fuzzy-logicbased support tools

969 
IMDS

121,5

970

Figure 2.

Different types of decision support tools for the manufacturing reshoring decisionmaking process making process itself, five types of decision-support tools can be distinguished (Figure 2). In the first step of the decision-making process, feasibility evaluation tools could help firms to continue on the most promising projects and reject less favorable ones. In the second step, performance evaluation tools could help firms to evaluate the performance of the current supply chain setup. In the third step, scenario generation tools could help firms identify feasible reshoring scenarios. In the fourth step, scenario evaluation tools could help firms evaluate the identified scenarios. For instance, a decision-support tool for initial evaluation, a stepwise decision-support tool for continuous evaluation or a decision-support tool for final evaluation. The decision-support tool for initial evaluation or screening could also be used as a feasibility tool in the first phase. In the fifth and final step of the decision-making process, scenario visualization tools could help firms visualize the evaluated scenarios for the decisionmakers.

\subsection{Fuzzy logic}

Fuzzy logic has varying and multiple degrees of truth values, as opposed to conventional Boolean logic, which has only completely true and completely false values (Zadeh, 1965). This allows fuzzy logic to express human-like statements in order to understand, represent and handle vagueness and imprecision, using human-like reasoning (Ross, 2017). When objects are expressed in fuzzy logic, they can be seen as a continuous grade of membership, with each object having a membership grade from zero to one. Fuzzy logic systems use this logic and the main application of such systems is decision-making. The system typically consists of four functional parts (Lee, 1990; Yazdanbakhsh and Dick, 2018). The first part, the fuzzifier, transforms the crisp input data into fuzzy data by performing scale mapping that transfers the crisp inputs to their corresponding grade of membership. The second part, the knowledge base, consists of all knowledge from the application domain. It includes a database with membership functions and a database with fuzzy inference (or if-then) rules (i.e. rule base). The third part, the inference engine, implements inference mechanisms, mostly derived from Boolean logic, which fires the rules from the knowledge base and combines them to obtain fuzzy output, which has the capability to perform human-like decisions. The fourth and final part, the defuzzifier, transforms the resulting fuzzy output data into crisp output data by performing scale mapping that transforms the fuzzy output into a precise number. The defuzzifier uses one among numerous defuzzification methods that exist for different applications. The method should be chosen according to computational simplicity (Esogbue and Song, 2003; Talon and Curt, 2017).

The development of fuzzy logic systems requires the selection of appropriate inference functions (Syn et al., 2011). These functions pertain to the basic inference steps: AND method; OR method; implication; aggregation and defuzzification. The AND as well as OR methods take place within the antecedents of the fuzzy if-then rule. The AND method results either in minimum (min) or product (prod) value of the antecedents within the rule. On the other hand,

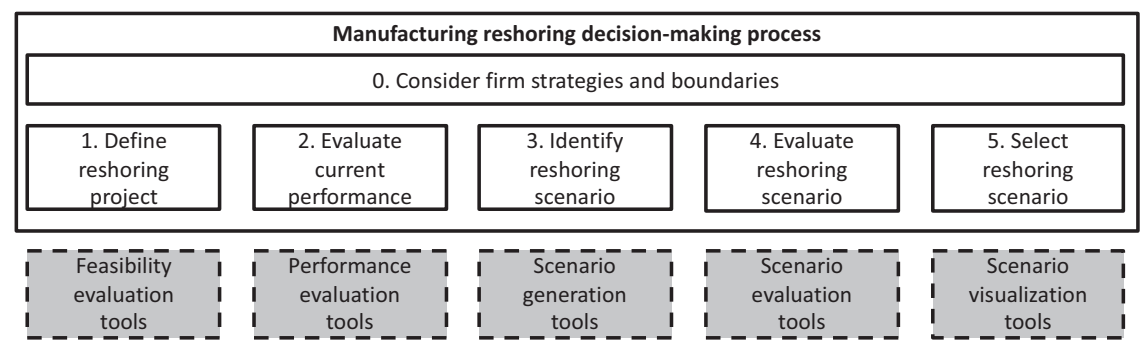


the OR method results in the maximum (max) value of the two variables within the rule. The results of the antecedents affect the degree to which the consequent is fuzzified. This degree can be determined by the implication step. Within the implication step, there exits the minimum (min) function such that the consequent is shortened, and a product (prod) function such that the consequent is scaled. The implication method is applied after specifying the rule weights. The aggregation step determines how the consequents of different rules are combined. In this step, the consequents are combined into one single output fuzzy set. It is necessary that the chosen operation is changeable as it should not matter in which way the rules are combined. Therefore maximum (max) and sum are appropriate. Finally, within the defuzzification step, centroid results in the center of the output fuzzy set, while the middle-ofmaximum (Mom) results in the average of the maximum of the output fuzzy set (MATLAB, 2018). The combination of above functions leads to multiple inference settings (Syn et al., 2011).

One of the main issues in fuzzy logic modeling is the tradeoff between interpretability and accuracy (Cordón, 2011; Shukla and Tripathi, 2012). Accuracy is defined as the model's ability to exactly represent the real system, while interpretability is defined as the model's ability to behave in an understandable way (Casillas et al., 2013). This tradeoff can be handled in two ways. One way is to make already interpretable parts more flexible, so that the accuracy is improved without losing interpretability. Another way is to put restrictions on already accurate parts, so that interpretability is increased (Casillas et al., 2013). The accuracy can be improved by tuning the type and shape of membership functions (Cordón and Herrera, 2000; Sambariya and Prasad, 2017), changing the settings in the fuzzy logic system (Syn et al., 2011), learning the number of linguistic labels (Casillas et al., 2013), using rule weights (Chen et al., 2016), or using linguistic variable weights (Hilletofth et al., 2019b). The interpretability can be improved by reducing the number of fuzzy rules or linguistic labels (i.e. readability), or by using linguistic labels that have consistent semantics for human users (i.e. comprehensibility) (Cordón, 2011). The abovementioned ways can also be combined to improve accuracy and interpretability.

In order to improve both interpretability and accuracy, various concepts have been studied to optimize the fuzzy rule base (Cordón and Herrera, 2000; Gacto et al., 2011; Tan et al., 2019). A complete set of fuzzy rules can increase accuracy, but decrease the rule interpretability (Cordón, 2011), whereas reducing the number of rules and linguistic variables can increase interpretability (Zhou and Gan, 2008). The selection of rules can also use a variety of hybrid approaches (Alcalá et al., 2006). Novel concepts that have been explored to improve this trade-off in the manufacturing reshoring domain include relative linguistic labels, high-level rules and linguistic variable weights (Hilletofth et al., 2019b). Relative linguistic labels (e.g. positive, neutral and negative) are interpreted more consistently among human decision-makers than absolute linguistic labels. They also eliminate the need to create specific linguistic labels for each variable and ensure the consistency of the fuzzy rule. High-level rules are reduced rules consisting of only few variables and which are more instinctive to the domain expert. It is proposed that high-level rules have high interpretability as they are the most meaningful rules in the system (Hilletofth et al., 2019b). Linguistic variable weights are values assigned to the linguistic variable so that the consequent can be assigned automatically. Using interpolation, the linguistic variable weights can be used to create a complete set of rules to achieve high accuracy (Hilletofth et al., 2019b).

\section{Fuzzy-logic-based support tools for initial screening of manufacturing reshoring decisions}

Two fuzzy-logic-based support tools for initial screening of manufacturing reshoring decisions are developed together with experts from a Swedish manufacturing firm.
Fuzzy-logicbased support tools 
IMDS

121,5

\section{2}

The manufacturing firm develops, manufactures and sells different kinds of transportation equipment. The Swedish plant is in charge of the final assembly. In recent years, the firm has started to reshore component manufacturing back to Sweden due to cost, lead-time and flexibility issues and moved toward a customization strategy which favors a rapid and flexible supply chain design. The support tools were created using the fuzzy logic toolbox found in MATLAB ${ }^{\circledR}$ R2018a (MATLAB, 2018), and was based on knowledge gained from the involved reshoring experts. The primary reason for developing a knowledge-driven (or expert) decision-support tool is that most of the available knowledge in this decision-making context is typically found in domain experts. This was also confirmed by the involved reshoring experts from the manufacturing company (e.g. limited amount of data on reshoring projects are stored in databases). In total eight experts, representing the senior management team of company were included as participants. This group is in charge of the final decision to reshore or not inside the company. The tool development process consisted of five steps and is adapted from a previously used procedure (Hilletofth $e$ t al., 2019b). The first support tool uses a complete rule base while the second uses a reduced rule base.

\subsection{Define linguistics variables}

The first step in developing the fuzzy-logic-based support tools is to define the linguistic variables. The goal of the proposed initial screening tools is to recommend further evaluation of a reshoring decision or not. The idea is to identify the most promising opportunities and put efforts into those and not waste time on less promising opportunities. According to the involved manufacturing reshoring experts, only one output linguistic variable with two values is needed in such an initial screening context. When it comes to the input variables, the involved reshoring experts argued that a screening tool could take departure from various sets of decision criteria including competitiveness, availability of resources and strategic orientation of the firm. The sets of criteria could also be addressed on a main-criteria or sub-criteria level.

For the purpose of investigating the suitability of fuzzy-logic-based support tools for initial screening of manufacturing reshoring decisions, the reshoring experts proposed that competitiveness criteria on a main-criteria level constitutes a suitable starting point. The main argument was that the competitiveness criteria provide a holistic view on how to create competitiveness, which is the primary objective of all manufacturing reshoring decisions. The relevance of the competitiveness criteria is also supported in the manufacturing reshoring literature (Benstead et al., 2017; Srai et al., 2016). Competitiveness criteria were chosen as input linguistic variables in both of the support tools. The developed support tools in total include six primary competitiveness criteria including cost, quality, time, flexibility, innovation and sustainability (Figure 3). There were also several sub-criteria; however, the developed support tools only considers the primary criteria level.

Figure 3.

The six reshoring criteria with their corresponding subcriteria

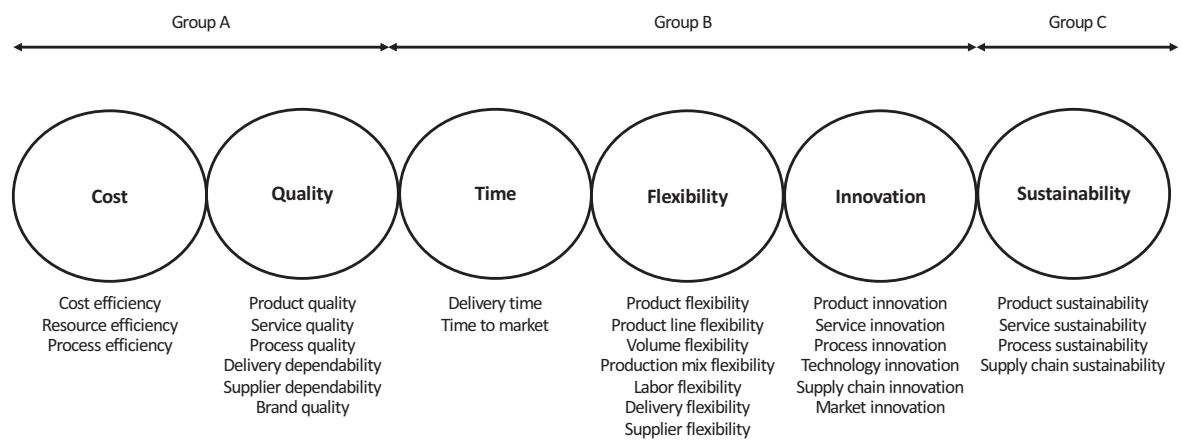


The different criteria were grouped according to their relative importance in a manufacturing reshoring decision by the involved reshoring experts. This was done during a joint workshop where all the involved experts participated. The workshop took departure from the criteria framework presented in Figure 3. According to the involved reshoring experts, the relative importance may differ in various decision-making situations. For example, different firms could assign different importance to the criteria. Hence, the grouping according to the importance should be specified for the particular firm and for the particular decision-making situation. The reshoring experts were involved in assigning the relative importance of the reshoring criteria which ended up in three groups (Figure 3). The decision-making situation considered by the experts was the initial screening in their own operations and the reshoring object was component manufacturing. Cost and quality were assigned the highest importance, time, flexibility, and innovation medium importance and sustainability the lowest importance. The grouping is supported by recent empirical research on critical operations capabilities in a high cost environment (Sansone et al., 2017, 2020) as well as with existing reshoring research which often considers cost and quality as the primary drivers for reshoring to high-cost environments (Engström et al., 2018a, b; Heikkilä et al., 2018; Johansson and Olhager, 2018).

\subsection{Define linguistics labels and membership functions}

The second step in developing the fuzzy-logic-based support tools was to define the linguistic labels and the corresponding membership functions. For both the developed support tools, relative linguistic labels were used (Hilletofth et al., 2019b). Three relative labels (i.e. positiveneutral-negative) were used in both of the support tools. Relative labels have three primary advantages. First, the same relative labels can be used for all the linguistic variables in a specific application, without a need to create unique and specific labels for each variable. Second, the inherent meaning of a relative label is the same to any user and third, they eliminate the need for absolute or concrete values, thus keeping the number of labels down. This increases the interpretability of the fuzzy rules and reduces the design complexity.

The corresponding membership functions were defined for each linguistic label. The choice of membership function affects the performance of the support tool and the smoothness of its input-output surface (Sambariya and Prasad, 2017). A linguistic variable could be represented by a countless number of membership functions depending on their type and shape. In both of the support tools, the six input criteria are represented by three Gaussian-type membership functions, while the output linguistic variable is represented by two Gaussian-type membership functions (Figure 4). The choice of Gaussian-type membership functions is supported by the small number of linguistic labels (Sambariya and Prasad, 2017) and the advantage of being smooth (Syn et al., 2011).

The shape of the membership functions is the same for all six linguistic variables in each of the two support tools. The reshoring experts' knowledge was used to specify the type and shape of the membership function that suited the application. This kind of approach in developing fuzzy-logic-based tools has been demonstrated before (e.g. Govindan et al., 2020). The Gaussian membership function depends on two parameters, the standard deviation $(\sigma)$ and center of the peak $(c)$ (Cpałka, 2017; Ross, 2017). It is necessary to set appropriate values of the membership function parameters, and this was done using a trial-and-error method in collaboration with the reshoring experts. The values entered in the fuzzy logic toolbox are shown in Table 1.

\subsection{Define fuzzy rules}

The third step in developing the fuzzy-logic-based support tools was to define the fuzzy rules. In the first support tool, a complete fuzzy rule base was created. A three-step process
Fuzzy-logicbased support tools 
IMDS

\section{1,5}

\section{4}

Figure 4.

The membership functions used for input and output linguistic variables in both support tools
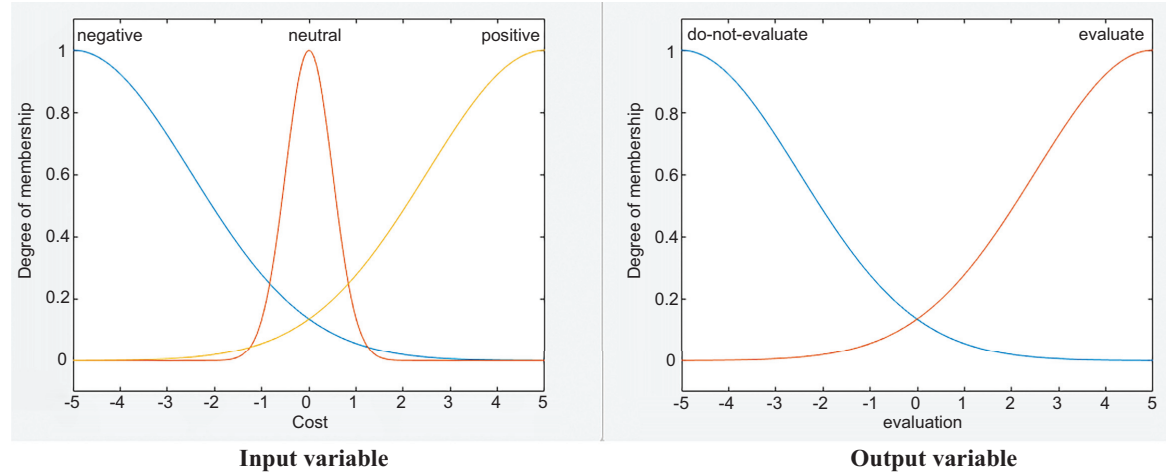

suggested previously by Hilletofth et al. (2019b) was used (Figure 5). A weight was assigned to each linguistic variable, based on its relative importance. The weights were assigned by the reshoring experts, after which, the complete fuzzy rule base was designed. The number of fuzzy rules in the complete rule base is $3^{6}=729$ with six linguistic variables and three linguistic labels for each variable. Finally, the consequent part of each fuzzy rule was calculated by summing the linguistic variable weights in the rule. The advantage of this semiautomatic approach is that the consequent for all the fuzzy rules in a complete set can rapidly be assigned without human interference (Hilletofth et al., 2019b). Hence, linguistic variable weights help to reduce the complexity when designing the fuzzy rules.

In the second support tool a reduced fuzzy rule base was created. The three-step process suggested by Hilletofth et al. (2019b) was also used in this situation (Figure 6). To begin with, a weight was assigned to each linguistic variable that represents the relative importance of the variable. The weights were assigned by the reshoring experts in the same way as the first support tool. High-level rules were then designed by the reshoring experts based on the variable weights. In total, 42 high-level rules were created. Finally, the 42 high-level rules were translated into fuzzy rules. In total, 156 fuzzy rules were translated from 42 high-level rules. The advantage of the high-level rules approach is that the reshoring experts only need to focus on the high-level rules that are relevant to the problem and that are more intuitive to them (Hilletofth et al., 2019b). High-level rules help to increase the interpretability of the fuzzy rules and to reduce the complexity of designing them.

\subsection{Configure the fuzzy logic system}

The fourth step in developing the fuzzy-logic-based support tools was to configure the tools. The toolbox used provided multiple setting for each parameter, although, only the most relevant settings for each parameter were considered, based on the literature (e.g. Castro and Delgado, 1996; Sadjadi et al., 2018; Syn et al., 2011). In total, 16 inference settings were used in both of the support tools (Table 2). It is important that note that the OR method did not impact the support tools, since there were no OR operations used in the designed fuzzy rules. The reason for this is that the involved experts did not consider the choices in this way. One competitiveness criteria could not be replaced by another, instead all of them must be related to one another.

The developed support tools generate an output in the form of a decision recommendation. The recommendation should be as close as possible to those of the reshoring experts. The 
input for each of the two support tools were 30 decision scenarios that consisted of six decision criteria (Table 3). The range of the input values of the six criteria was fixed from a scale of -5 to +5 . +5 denotes that the criterion would be affected very positively if reshoring occurred, while -5 denotes that the criterion would be affected very negatively if reshoring occurred. The range of the output value was also fixed from a scale of -5.00 to +5.00 , where a value between -5.00 and 0.00 suggest "do not evaluate" while a value 0.01 to +5.00 suggest "evaluate further". A higher or lower value provides a stronger suggestion as to whether to further evaluate the reshoring opportunity or not.

Out of the 30 decision scenarios, fifteen were designed by the involved reshoring experts while the other fifteen were designed by fuzzy logic experts in order to further test the support tools. The scenarios created by the fuzzy logic experts are more problematic in nature (e.g. completely neutral, weakly positive or weakly negative). For each decision scenario, the reshoring experts provided an opinion of how they would evaluate the respective scenario (average) and is shown in the column Experts' opinion $\left(y_{j}\right)$ in the scenario table.

\subsection{Evaluate tool accuracy}

In the fifth and final step, the accuracy of the developed tools was evaluated in alignment with the opinion of the experts. This step depends largely on the experts' evaluation of the reshoring scenario, and their decision on how they perceive a particular scenario. The motivation for this is the lack of data on manufacturing reshoring evaluations, which makes the experts' opinion the best available benchmark. The accuracy between the tool and reshoring experts' opinion were calculated using three error metrics: decision accuracy (DA), the mean absolute error (MAE) and the root mean squared error (RMSE). These metrics are shown in Equations. (1), (2) and (3) respectively. The DA indicates the percentage of "correct" decisions made by the tool in alignment with the reshoring experts' opinion. The MAE and RMSE measures the error in values between the tool's output $\left(\hat{y}_{j}\right)$ and the experts' opinion $\left(y_{j}\right)$

$$
\begin{gathered}
\mathrm{DA}=\frac{\text { Number of correct decisions }}{\text { Total number of decisions }} \times 100 \\
\text { MAE }=\frac{1}{30} \sum_{j=1}^{30}\left|\widehat{y}_{j}-y_{j}\right| \\
\mathrm{RMSE}=\sqrt{\frac{1}{30} \sum_{j=1}^{30}\left(\widehat{y}_{j}-y_{j}\right)^{2}}
\end{gathered}
$$

The tools are evaluated using the metrics from two perspective: (1) individual settings and (2) overall tool. The individual settings perspective means determining the best performing tool by comparing best and worst performing settings. The overall tool perspective means

\begin{tabular}{llcr}
\hline Type & Linguistic label & Standard deviation $(\sigma)$ & Center of peak $(c)$ \\
\hline \multirow{2}{*}{ Input } & Negative & 2.5 & -5 \\
& Neutral & 0.5 & 0 \\
& Positive & 2.5 & 5 \\
Output & Do-not-evaluate & 2.5 & -5 \\
& Evaluate & 2.5 & 5
\end{tabular}

Fuzzy-logicbased support tools 
IMDS

121,5

976

Figure 5.

Fuzzy rules design in

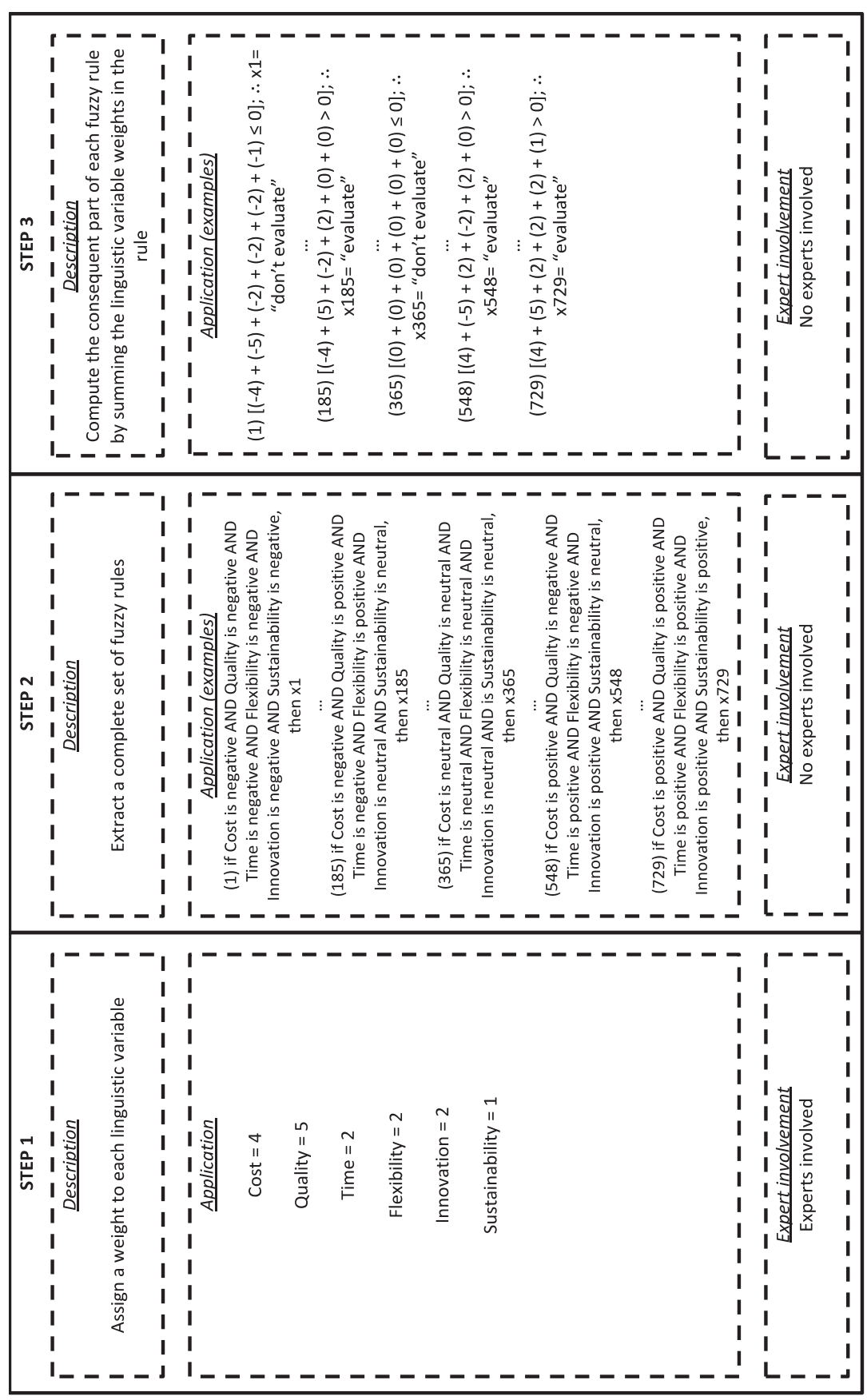

the first support tool 
Fuzzy-logicbased support tools

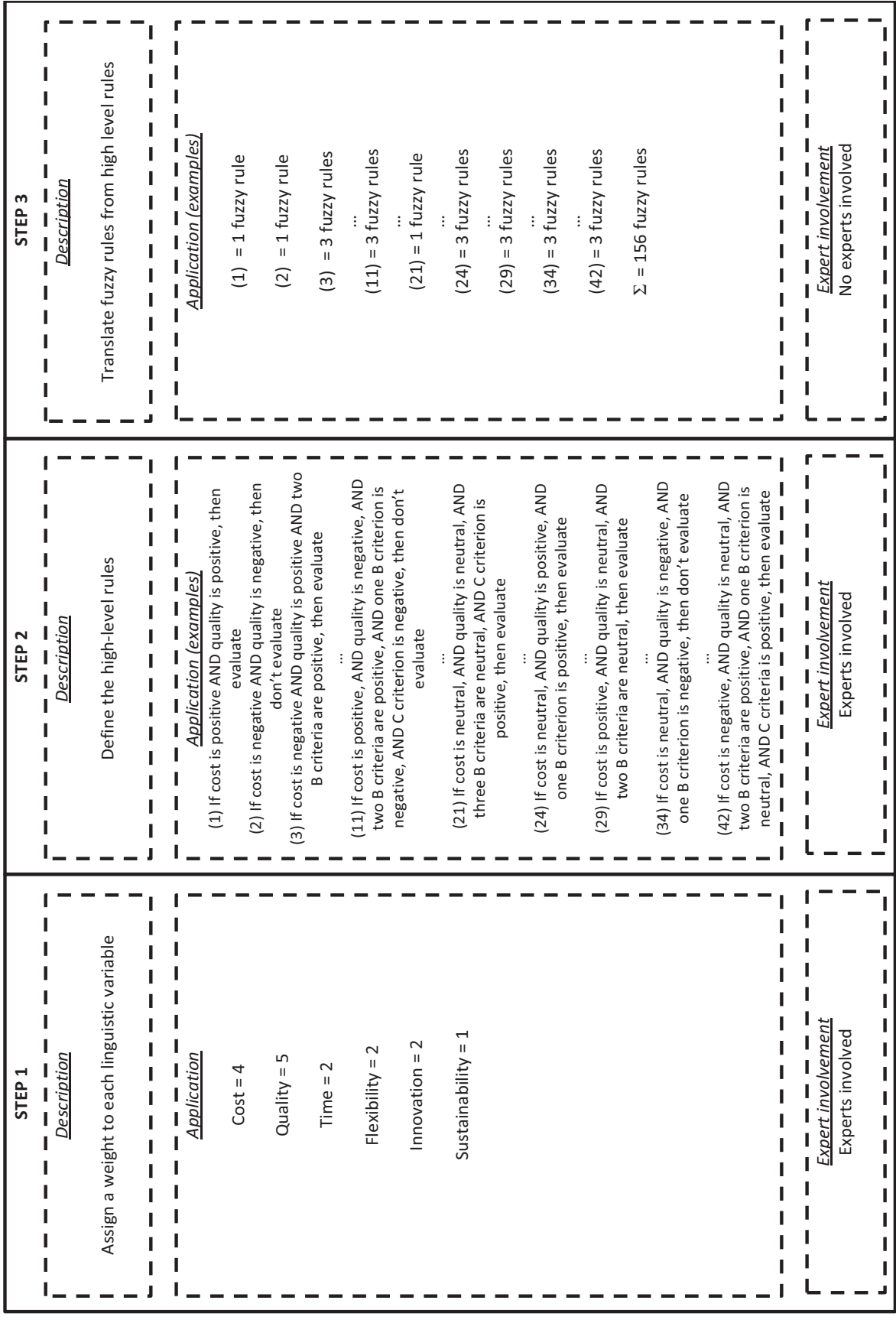

Figure 6. Fuzzy rule design in the second support tool 


\begin{tabular}{|c|c|c|c|c|c|c|}
\hline $\begin{array}{l}\text { IMDS } \\
121,5\end{array}$ & Setting & $\begin{array}{l}\text { AND } \\
\text { method }\end{array}$ & OR method & Implication method & $\begin{array}{l}\text { Aggregation } \\
\text { method }\end{array}$ & Defuzzification method \\
\hline \multirow[b]{5}{*}{978} & 1 & Min & $\operatorname{Max}$ & Min & Max & Centroid \\
\hline & 2 & Min & $\operatorname{Max}$ & Min & Max & Mom \\
\hline & 3 & Min & $\operatorname{Max}$ & Min & Sum & Centroid \\
\hline & 4 & Min & Max & Min & Sum & Mom \\
\hline & 5 & Min & Max & Prod & $\operatorname{Max}$ & Centroid \\
\hline & 6 & Min & Max & Prod & $\operatorname{Max}$ & Mom \\
\hline & 7 & Min & Max & Prod & Sum & Centroid \\
\hline & 8 & Min & Max & Prod & Sum & Mom \\
\hline & 9 & Prod & $\operatorname{Max}$ & Min & Max & Centroid \\
\hline & 10 & Prod & Max & Min & $\operatorname{Max}$ & Mom \\
\hline & 11 & Prod & $\operatorname{Max}$ & Min & Sum & Centroid \\
\hline & 12 & Prod & Max & Min & Sum & Mom \\
\hline Table 2 & 13 & Prod & Max & Prod & Max & Centroid \\
\hline The fuzzy inference & 14 & Prod & $\operatorname{Max}$ & Prod & $\operatorname{Max}$ & Mom \\
\hline settings used in both & 15 & Prod & Max & Prod & Sum & Centroid \\
\hline support tools & 16 & Prod & $\operatorname{Max}$ & Prod & Sum & Mom \\
\hline
\end{tabular}

determining the best performing tool by comparing the average across all settings. The reason for evaluating the tools in this way is to make the comparison of them as robust as possible and both of the evaluations are relevant for different reasons. A decision-maker will never use all of the settings but instead try to find the best setting for the decision-making context which supports the first perspective. On the other hand, it is of significant value if the tools could be used in many decision-making contexts supporting the second perspective.

\section{Results from the fuzzy-logic-based support tools}

The evaluation of the developed support tools is presented below. The tools are first evaluated individually and thereafter compared with each other. The results from the first support tool are shown in Table 4 and from the second support tool in Table 5. In both cases, each decision scenario is evaluated by comparing the tool output with the experts' opinion and this is done for all the sixteen settings. For each setting DA, MAE and RMSE are calculated. Conflict between the tool output and the experts' opinion is indicated with gray color.

\subsection{Tool output}

As can be noted in Table 4, a conflict between tool output and experts' opinion only occurred in 9 out of 480 decision outputs in the first support tool. This indicates that there is strong alignment between tool outputs and experts' opinions when it comes to DA (98\%). Conflicts were only observed in 3 out of 30 scenarios (10\%), including scenarios 17, 20 and 25 . Scenario 17 was the most problematic scenario since it generated conflicts in five settings (i.e. 3, 7, 8, 15 and 16). In this scenario, quality and sustainability criteria are strongly negative, while other criteria are weakly positive. The second most problematic scenario (Scenario 20) generated conflicts in three settings (i.e. 3, 7 and 8). In this scenario quality and sustainability criteria are strongly positive, while other criteria are weakly negative (i.e. linguistically opposite to Scenario 17). The third most problematic scenario (Scenario 25) generated conflict in only one setting (i.e. 4). In this scenario, quality and innovation are neutral, cost and sustainability are positive, while time and flexibility were negative.

The scenarios with conflicts correspond to a set of values $\{-3,3\}$ by the reshoring experts. However, this range of values is not exclusively limited to conflicting scenarios as 


\begin{tabular}{|c|c|c|c|c|c|c|c|c|c|}
\hline \multirow[b]{2}{*}{ Scenario } & \multirow[b]{2}{*}{ Cost } & \multirow[b]{2}{*}{ Quality } & \multirow[b]{2}{*}{ Time } & \multicolumn{3}{|c|}{ Reshoring criteria } & \multirow{2}{*}{$\begin{array}{l}\text { Experts' opinion } \\
\qquad\left(y_{j}\right)\end{array}$} & \multirow{2}{*}{$\begin{array}{l}\text { Experts' } \\
\text { decision }\end{array}$} & \multirow{2}{*}{$\begin{array}{l}\text { Fuzzy-logic- } \\
\text { based support }\end{array}$} \\
\hline & & & & Flexibility & Innovation & Sustainability & & & \\
\hline 1 & -5 & -1 & -3 & -2 & -3 & 3 & -5 & Do not evaluate & \\
\hline 2 & 2 & 5 & -1 & 3 & 4 & 1 & 4 & Evaluate & \\
\hline 3 & -3 & -4 & -3 & 0 & 4 & -1 & -4 & Do not evaluate & \\
\hline 4 & 3 & -4 & 0 & -3 & -5 & -3 & -4 & Do not evaluate & \\
\hline 5 & -4 & -2 & 5 & -1 & 0 & 5 & -4 & Do not evaluate & 979 \\
\hline 6 & 4 & 2 & -4 & 2 & 2 & -5 & 4 & Evaluate & 989 \\
\hline 7 & -4 & 2 & 1 & 0 & 2 & 5 & 3 & Evaluate & \\
\hline 8 & 2 & -1 & 3 & 0 & 1 & 5 & 3 & Evaluate & \\
\hline 9 & 3 & 5 & 5 & 2 & 5 & -3 & 5 & Evaluate & \\
\hline 10 & -3 & -5 & 3 & -2 & 5 & -2 & -4 & Do not evaluate & \\
\hline 11 & 0 & 0 & 0 & 0 & 0 & 0 & -3 & Do not evaluate & \\
\hline 12 & 3 & -4 & 2 & -2 & -2 & 2 & -3 & Do not evaluate & \\
\hline 13 & -5 & 0 & 3 & 5 & 5 & 4 & 3 & Evaluate & \\
\hline 14 & -5 & 4 & 2 & -1 & -4 & 3 & -3 & Do not evaluate & \\
\hline 15 & -2 & -5 & -5 & -2 & -5 & 5 & -5 & Do not evaluate & \\
\hline 16 & -3 & 5 & 5 & 3 & 5 & -3 & 4 & Evaluate & \\
\hline 17 & 1 & -5 & 1 & 1 & 1 & -5 & 3 & Evaluate & \\
\hline 18 & -5 & 1 & -5 & -5 & -5 & 1 & -3 & Do not evaluate & \\
\hline 19 & 5 & -1 & 5 & 5 & 5 & -1 & 3 & Evaluate & \\
\hline 20 & -1 & 5 & -1 & -1 & -1 & 5 & -3 & Do not evaluate & \\
\hline 21 & -2 & -5 & -5 & -2 & -5 & 5 & -5 & Do not evaluate & \\
\hline 22 & 5 & -4 & 1 & 3 & 3 & 5 & 4 & Evaluate & \\
\hline 23 & 2 & 2 & 3 & 1 & 5 & 3 & 5 & Evaluate & \\
\hline 24 & -5 & -5 & 5 & -4 & -5 & 3 & -4 & Do not evaluate & \\
\hline 25 & 4 & 0 & -5 & -2 & 0 & 3 & 3 & Evaluate & \\
\hline 26 & -4 & 0 & -5 & 4 & -3 & 1 & -3 & Do not evaluate & \\
\hline 27 & 1 & 1 & 5 & 1 & -2 & -3 & 4 & Evaluate & Table 3. \\
\hline 28 & -4 & 4 & -4 & 4 & 2 & -2 & 3 & Evaluate & The decision scenarios \\
\hline 29 & 1 & -3 & 5 & -4 & -4 & 3 & -3 & Do not evaluate & used in both of the \\
\hline 30 & 0 & -4 & 2 & -2 & 4 & 0 & -3 & Do not evaluate & support tools \\
\hline
\end{tabular}

some of the non-conflicting scenarios have also evaluated to be in set $\{-3,3\}$ by the reshoring experts. It is possible that the conflicts arise from the weights of the criteria based on which the 729 fuzzy rules were generated. On the settings level, 10 out of 16 settings returned a DA of $100 \%$, three settings returned a DA of $97 \%$ and three settings returned a DA of $93 \%$. The best performing setting is Setting 2 ( $\min$; max; min; $\max$; mom; $\mathrm{DA}=100 \%$; $\mathrm{MAE}=0.65$; RMSE $=0.93$ ), followed by Setting 13 (prod; max; prod; max; centroid; DA $=100 \%$; MAE $=0.98$; RMSE $=1.19$ ). The worst performing setting is Setting 3 (min; max; min; sum; centroid; $\mathrm{DA}=93 \%$; MAE $=2.45$; RMSE $=2.59$ ), followed by Setting 11 (prod; max; min; max; centroid; $\mathrm{DA}=100 \%$; $\mathrm{MAE}=2.32 ; \mathrm{RMSE}=2.44$ ).

As noted in Table 5 , a conflict between tool output and experts' opinion occurred in 25 out of 480 decision outputs in the second support tool. This shows that there is strong alignment between tool outputs with experts' opinions when it comes to DA (95\%). Conflicts were only observed in 4 out of 30 scenarios (13\%), including scenarios 11, 17, 20 and 25 . The last three scenarios also generated conflicts in the first support tool. In Scenario 11, all the criteria are neutral. The tool returns a value of 0.01 which suggests a weak decision to evaluate, thereby conflicting the experts' opinion in one setting (i.e. 3). In Scenario 17, conflict was encountered in twelve settings (i.e. 3, 4, 7-16), while in Scenario 20, conflict was encountered in eleven settings (i.e. 3, 7-16). Scenario 25 only returned conflict in one setting (i.e. 4). Similar to the first support tool, all these scenarios correspond to a value $\{-3,3\}$ by the reshoring experts. 
IMDS

121,5

On the settings level, 4 out of the 16 settings returned a DA of $100 \%$, eleven settings returned a DA of $93 \%$ and one settings returned a DA of $90 \%$. The best performing setting is Setting $2(\mathrm{DA}=100 \%$; MAE $=0.62 ; \mathrm{RMSE}=0.89)$, followed by Setting 10 (prod; max; min; $\max ;$ mom; $\mathrm{DA}=93 \%$; MAE $=1.09 ; \mathrm{RMSE}=1.65$ ). The worst performing setting depends on whether MAE or RMSE is considered. Based on MAE, the worst performing setting is Setting $3(\mathrm{DA}=90 \%$; MAE $=2.07$; RMSE $=2.26)$, followed by Setting $11(\mathrm{DA}=93 \%$; MAE $=1.82 ;$ RMSE $=2.00$ ). Based on RMSE, the worst performing Settings are 8, 14 and 16 $(\mathrm{DA}=93 \% ; \mathrm{MAE}=1.73 ; \mathrm{RMSE}=2.52)$.

\subsection{Tool comparison}

In order to compare the developed support tools based on the overall performance, average DA, MAE and RMSE is calculated for each tool (Table 6). For example, the average DA is $98 \%$ for the first support tool and $95 \%$ for the second support tool. This suggests that the first support tool has a higher decision accuracy across the various settings. However, the average MAE suggests that the second support tool performs best while the average RMSE suggests the opposite. To further evaluate the performance of the developed tools, a two-sample $t$-test was conducted for MAE and RMSE. No statistically significant differences were found between the two support tools [1]. The developed support tools are also compared under the effect of different inference functions (Table 6). For instance, when min operator is used for the AND function, the second support tool (DA $=96 \%$; $\mathrm{MAE}=1.45 ; \mathrm{RMSE}=1.76$ ) performs slightly better than the first support tool (DA $=97 \%$; MAE $=1.55$; RMSE $=1.85$ ). Based on the comparison above, it can be concluded that the developed support tools perform similarly.

In order to compare the developed support tools across different settings, the DA, MAE and RMSE values of all the settings are compared (Figure 7). From the comparison it is evident that Setting 2 has the highest DA of 100\% and the lowest MAE and RMSE values, and hence is the preferred setting in both of the developed support tools. This suggests that Setting 2 is able to best approximate the reasoning of the involved reshoring experts. The comparison also shows that for Settings 7-16, there is a higher difference between MAE and RMSE values than for Settings 1-6, indicating a higher variance in the error. Based on the findings that the developed support tools perform similarly and that Setting 2 performs best in both the support tools and also better than the other settings, it can be concluded that it does not matter whether a complete or reduced rule base is used, it is important that the right setting is selected.

The developed support tools perform similarly with regard to accuracy even though the second support tool used fewer fuzzy rules. The second support tool used in total 156 fuzzy rules while the first support tool used 729 fuzzy rules. The smaller number of fuzzy rules used in the second tool provides increased interpretability. A small set of high-level rules were proposed by the involved reshoring experts and these were later translated into 156 fuzzy rules, making the overall structure easier to grasp for decision-makers. This also reduced the amount of time needed from the reshoring experts and the researchers when designing the fuzzy rules. Hence, for the purpose of initial screening of manufacturing reshoring decisions, the second support tool is more preferable since it uses less resources and is more interpretable, and still perform similarly.

\section{Discussion}

There is a clear need for more advanced decision-support tools in the manufacturing reshoring domain (Barbieri et al., 2018; Hilletofth et al., 2019b; Stentoft et al., 2016). The complexity inherent in this kind of decision-making situation requires advanced decision- 


\begin{tabular}{|c|c|c|c|c|c|c|c|c|c|c|c|c|c|c|c|c|}
\hline \multirow[t]{2}{*}{ Scenario } & \multicolumn{16}{|c|}{ Tool output $\left(\hat{y}_{j}\right)$} \\
\hline & $\begin{array}{l}-1 \\
\stackrel{\infty}{\infty} \\
\stackrel{E}{ \pm} \\
\sim\end{array}$ & 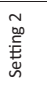 & 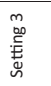 & 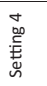 & 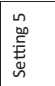 & 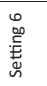 & 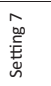 & 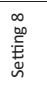 & 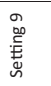 & $\begin{array}{l}\text { 엄 } \\
\stackrel{\text { D. }}{E} \\
\stackrel{E}{ \pm}\end{array}$ & 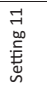 & 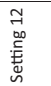 & $\begin{array}{l}m \\
\stackrel{m}{0} \\
\stackrel{0}{0} \\
\stackrel{E}{0} \\
\sim\end{array}$ & 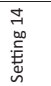 & 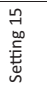 & $\begin{array}{l}\stackrel{0}{ } \\
-1 \\
\stackrel{0}{0} \\
\stackrel{E}{ \pm} \\
\sim\end{array}$ \\
\hline 1 & -2.27 & -3.00 & -1.21 & -2.00 & -2.95 & -5.00 & -2.45 & -5.00 & -1.49 & -2.00 & -1.22 & -2.00 & -3.04 & -5.00 & -3.04 & -5.00 \\
\hline 2 & 2.27 & 3.00 & 1.41 & 2.00 & 2.95 & 5.00 & 2.69 & 5.00 & 1.19 & 1.65 & 0.83 & 1.65 & 3.04 & 5.00 & 3.04 & 5.00 \\
\hline 3 & -2.27 & $\mid-3.00$ & -1.37 & -2.00 & -2.95 & -5.00 & -2.42 & -5.00 & -1.89 & -2.50 & -1.45 & -2.50 & -3.04 & -5.00 & -3.03 & -5.00 \\
\hline 4 & -2.85 & -4.00 & -1.96 & -3.00 & -3.01 & -5.00 & -2.84 & -5.00 & -2.44 & -3.20 & -2.08 & -3.00 & -3.04 & -5.00 & -3.03 & -5.00 \\
\hline 5 & -2.12 & $\mid-3.00$ & -1.32 & -1.50 & -2.71 & -5.00 & -2.13 & -5.00 & -1.84 & -2.50 & -1.38 & -1.55 & -2.86 & -5.00 & -2.81 & -5.00 \\
\hline 6 & 2.50 & 3.50 & 1.31 & 2.00 & 2.86 & 5.00 & 1.91 & 5.00 & 1.73 & 2.35 & 1.52 & 1.50 & 2.86 & 5.00 & 2.80 & 5.00 \\
\hline 7 & 1.70 & 3.00 & 0.68 & 1.00 & 2.11 & 5.00 & 1.03 & 5.00 & 1.53 & 2.05 & 1.06 & 1.35 & 2.86 & 5.00 & 2.63 & 5.00 \\
\hline 8 & 0.89 & 3.00 & 0.95 & 1.00 & 1.11 & 5.00 & 1.66 & 5.00 & 1.04 & 1.65 & 0.64 & 0.65 & 2.11 & 5.00 & 2.37 & 5.00 \\
\hline 9 & 2.63 & 3.50 & 2.08 & 3.50 & 3.04 & 5.00 & 2.85 & 5.00 & 2.26 & 2.95 & 2.12 & 2.95 & 3.04 & 5.00 & 3.04 & 5.00 \\
\hline 10 & -2.60 & -3.50 & -1.73 & -2.50 & -2.99 & -5.00 & -2.62 & -5.00 & -1.89 & -2.50 & -1.71 & -2.50 & -3.04 & -5.00 & -3.03 & -5.00 \\
\hline 11 & -2.17 & -5.00 & -0.14 & 0.00 & -2.40 & -5.00 & -0.22 & -5.00 & -2.17 & -5.00 & -0.40 & 0.00 & -2.40 & -5.00 & -0.82 & -5.00 \\
\hline 12 & -2.50 & -3.50 & -1.06 & -2.00 & -2.86 & -5.00 & -1.98 & -5.00 & -1.33 & -1.80 & -1.08 & -1.30 & -2.86 & -5.00 & -2.60 & -5.00 \\
\hline 13 & 1.94 & 4.00 & 1.61 & 3.00 & 2.17 & 5.00 & 2.07 & 5.00 & 2.18 & 3.90 & 1.91 & 2.80 & 2.40 & 5.00 & 2.35 & 5.00 \\
\hline 14 & -0.89 & -3.00 & -0.44 & -1.00 & -1.11 & -5.00 & -0.91 & -5.00 & -0.79 & -2.25 & -0.39 & -0.40 & -1.11 & -5.00 & -0.67 & -5.00 \\
\hline 15 & -2.63 & -3.50 & -2.00 & -3.50 & -3.04 & -5.00 & -2.81 & -5.00 & -2.22 & -2.90 & -2.05 & -2.90 & -3.04 & -5.00 & -3.04 & -5.00 \\
\hline 16 & 2.87 & 4.00 & 2.47 & 4.00 & 3.04 & 5.00 & 2.95 & 5.00 & 2.49 & 3.30 & 2.39 & 3.30 & 3.04 & 5.00 & 3.04 & 5.00 \\
\hline 17 & 0.89 & 3.00 & -1.24 & 0.00 & 1.11 & 5.00 & -2.30 & -5.00 & 0.42 & 1.05 & 0.05 & 0.25 & 1.11 & 5.00 & -1.20 & -5.00 \\
\hline 18 & -2.30 & -3.00 & -1.75 & -3.00 & -3.04 & -5.00 & -2.90 & -5.00 & -1.66 & -2.20 & -1.30 & -2.20 & -3.04 & -5.00 & -3.04 & -5.00 \\
\hline 19 & 2.30 & 3.00 & 1.75 & 3.00 & 3.04 & 5.00 & 2.89 & 5.00 & 1.66 & 2.20 & 1.30 & 2.20 & 3.04 & 5.00 & 3.03 & 5.00 \\
\hline 20 & -0.89 & -3.00 & 0.83 & 0.00 & -1.11 & -5.00 & 1.58 & 5.00 & -0.59 & -1.05 & -0.17 & -0.50 & -1.96 & -5.00 & -0.15 & -5.00 \\
\hline 21 & -2.63 & -3.50 & -2.00 & -3.50 & -3.04 & -5.00 & -2.81 & -5.00 & -2.22 & -2.90 & -2.05 & -2.90 & -3.04 & -5.00 & -3.04 & -5.00 \\
\hline 22 & 2.27 & 3.00 & 1.52 & 2.00 & 2.95 & 5.00 & 2.42 & 5.00 & 1.93 & 2.50 & 1.68 & 2.30 & 3.03 & 5.00 & 2.99 & 5.00 \\
\hline 23 & 2.12 & 3.00 & 0.93 & 1.50 & 2.71 & 5.00 & 1.73 & 5.00 & 1.32 & 1.80 & 1.03 & 1.80 & 3.04 & 5.00 & 3.03 & 5.00 \\
\hline 24 & -2.87 & -4.00 & -2.62 & -4.00 & -3.04 & -5.00 & -2.96 & -5.00 & -2.82 & -3.90 & -2.77 & -3.90 & -3.04 & -5.00 & -3.04 & -5.00 \\
\hline 25 & 1.53 & 3.50 & 0.54 & 0.00 & 1.80 & 5.00 & 0.86 & 5.00 & 1.97 & 3.15 & 1.21 & 1.30 & 2.40 & 5.00 & 1.87 & 5.00 \\
\hline 26 & -2.27 & -3.00 & -1.60 & -2.00 & -2.95 & -5.00 & -2.72 & -5.00 & -2.05 & -2.70 & -1.60 & -2.70 & -3.04 & -5.00 & -3.02 & -5.00 \\
\hline 27 & 0.89 & 3.00 & 0.31 & 1.00 & 1.11 & 5.00 & 0.56 & 5.00 & 0.68 & 1.10 & 0.32 & 0.60 & 2.11 & 5.00 & 1.76 & 5.00 \\
\hline 28 & 2.50 & 3.50 & 1.47 & 2.00 & 2.86 & 5.00 & 2.08 & 5.00 & 1.99 & 2.70 & 1.80 & 1.60 & 2.86 & 5.00 & 2.78 & 5.00 \\
\hline 29 & -2.27 & -3.00 & -1.45 & -2.00 & -2.95 & -5.00 & -2.37 & -5.00 & -1.89 & -2.50 & -1.64 & -2.10 & -3.01 & -5.00 & -2.98 & -5.00 \\
\hline 30 & -1.53 & -3.50 & -0.94 & -2.00 & -1.80 & -5.00 & -1.66 & -5.00 & -1.80 & -2.80 & -1.26 & -1.15 & -2.40 & -5.00 & -2.31 & -5.00 \\
\hline $\mathrm{DA}$ & $100 \%$ & $100 \%$ & $93 \%$ & $97 \%$ & $100 \%$ & $100 \%$ & $93 \%$ & $93 \%$ & $100 \%$ & $100 \%$ & $100 \%$ & $100 \%$ & $100 \%$ & $100 \%$ & $97 \%$ & $97 \%$ \\
\hline MAE & 1.59 & 0.65 & 2.45 & 1.67 & 1.18 & 1.33 & 1.81 & 1.73 & 1.95 & 1.37 & 2.32 & 1.81 & 0.98 & 1.33 & 1.23 & 1.53 \\
\hline RMSE & 1.74 & 0.93 & 2.59 & 1.96 & 1.40 & 1.53 & 2.16 & 2.52 & 2.11 & 1.61 & 2.44 & 2.01 & 1.19 & 1.53 & 1.56 & 2.08 \\
\hline
\end{tabular}

Note(s): Grey color indicating a conflict between tool and expert, and italic best performing setting
Fuzzy-logicbased support tools

981
Table 4.

Evaluation of output results from the first support tool 
IMDS

121,5

982

Table 5.

Evaluation of output results from the second support tool

\begin{tabular}{|c|c|c|c|c|c|c|c|c|c|c|c|c|c|c|c|c|}
\hline \multirow[t]{2}{*}{ Scenario } & \multicolumn{16}{|c|}{ Tool output $\left(\hat{y}_{j}\right)$} \\
\hline & 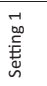 & 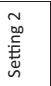 & $\begin{array}{l}m \\
\text { mo } \\
\text { E } \\
\stackrel{E}{E} \\
\sim\end{array}$ & 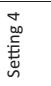 & 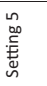 & 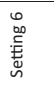 & 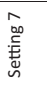 & $\begin{array}{l}\infty \\
\infty \\
\stackrel{\infty}{E} \\
\stackrel{N}{ \pm}\end{array}$ & 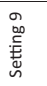 & 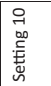 & 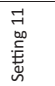 & 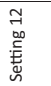 & $\begin{array}{l}m \\
\stackrel{m}{a} \\
\stackrel{0}{0} \\
\stackrel{E}{E} \\
\stackrel{N}{n}\end{array}$ & 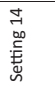 & 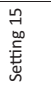 & 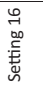 \\
\hline 1 & -2.27 & -3.00 & -1.81 & -2.00 & -2.95 & -5.00 & -2.84 & -5.00 & -2.30 & -3.00 & -1.87 & -3.00 & -3.04 & -5.00 & -3.04 & -5.00 \\
\hline 2 & 2.60 & 3.50 & 2.06 & 2.50 & 2.99 & 5.00 & 2.81 & 5.00 & 2.63 & 3.50 & 2.52 & 3.50 & 3.04 & 5.00 & 3.04 & 5.00 \\
\hline 3 & -2.85 & -4.00 & -2.22 & -3.00 & -3.01 & -5.00 & -2.66 & -5.00 & -2.82 & -3.90 & -2.78 & -3.90 & -3.04 & -5.00 & -3.03 & -5.00 \\
\hline 4 & -2.85 & -4.00 & -2.36 & -3.00 & -3.01 & -5.00 & -2.96 & -5.00 & -2.63 & -3.50 & -2.27 & -3.10 & -3.03 & -5.00 & -3.03 & -5.00 \\
\hline 5 & -2.50 & -3.50 & -1.38 & -2.00 & -2.86 & -5.00 & -1.78 & -5.00 & -2.56 & -3.45 & -2.42 & -2.50 & -3.00 & -5.00 & -2.88 & -5.00 \\
\hline 6 & 2.50 & 3.50 & 1.64 & 2.00 & 2.86 & 5.00 & 2.07 & 5.00 & 2.57 & 3.45 & 2.51 & 2.60 & 3.01 & 5.00 & 2.97 & 5.00 \\
\hline 7 & 1.70 & 3.00 & 1.43 & 1.00 & 2.11 & 5.00 & 2.27 & 5.00 & 1.09 & 2.05 & 0.95 & 0.55 & 1.71 & 5.00 & 2.24 & 5.00 \\
\hline 8 & 0.89 & 3.00 & 1.17 & 1.00 & 1.11 & 5.00 & 1.93 & 5.00 & 1.33 & 1.95 & 0.96 & 0.95 & 2.49 & 5.00 & 2.55 & 5.00 \\
\hline 9 & 2.87 & 4.00 & 2.69 & 4.00 & 3.04 & 5.00 & 3.00 & 5.00 & 2.87 & 4.00 & 2.79 & 4.00 & 3.04 & 5.00 & 3.04 & 5.00 \\
\hline 10 & -2.85 & -4.00 & -2.52 & -3.00 & -3.01 & -5.00 & -2.86 & -5.00 & -2.87 & -4.00 & -2.86 & -4.00 & -3.04 & -5.00 & -3.03 & -5.00 \\
\hline 11 & -2.17 & -5.00 & 0.01 & 0.00 & -2.40 & -5.00 & -0.01 & -5.00 & -2.17 & -5.00 & -0.43 & 0.00 & -2.40 & -5.00 & -0.78 & -5.00 \\
\hline 12 & -2.50 & -3.50 & -1.53 & -2.00 & -2.86 & -5.00 & -2.20 & -5.00 & -2.00 & -2.65 & -1.74 & -2.15 & -3.01 & -5.00 & -2.89 & -5.00 \\
\hline 13 & 1.94 & 4.00 & 1.80 & 3.00 & 2.17 & 5.00 & 2.35 & 5.00 & 1.94 & 4.00 & 1.78 & 3.00 & 2.17 & 5.00 & 2.32 & 5.00 \\
\hline 14 & -0.89 & -3.00 & -0.49 & -1.00 & -1.11 & -5.00 & -0.75 & -5.00 & -1.75 & -2.90 & -1.21 & -1.05 & -2.24 & -5.00 & -1.79 & -5.00 \\
\hline 15 & -2.63 & -3.50 & -2.27 & -3.50 & -3.04 & -5.00 & -2.98 & -5.00 & -2.63 & -3.50 & -2.41 & -3.50 & -3.04 & -5.00 & -3.04 & -5.00 \\
\hline 16 & 2.87 & 4.00 & 2.84 & 4.00 & 3.04 & 5.00 & 3.03 & 5.00 & 2.87 & 4.00 & 2.74 & 4.00 & 3.04 & 5.00 & 3.04 & 5.00 \\
\hline 17 & 0.89 & 3.00 & -0.77 & 0.00 & 1.11 & 5.00 & -1.38 & -5.00 & -1.40 & -2.00 & -0.88 & -1.00 & -2.54 & -5.00 & -2.49 & -5.00 \\
\hline 18 & -2.30 & -3.00 & -2.11 & -3.00 & -3.04 & -5.00 & -3.01 & -5.00 & -2.30 & -3.00 & -2.13 & -3.00 & -3.04 & -5.00 & -3.04 & -5.00 \\
\hline 19 & 2.30 & 3.00 & 1.98 & 3.00 & 3.04 & 5.00 & 3.00 & 5.00 & 2.30 & 3.00 & 2.02 & 3.00 & 3.04 & 5.00 & 3.04 & 5.00 \\
\hline 20 & -0.89 & -3.00 & 0.44 & 0.00 & -1.11 & -5.00 & 0.83 & 5.00 & 0.92 & 2.00 & 0.16 & 0.45 & 1.43 & 5.00 & 0.55 & 5.00 \\
\hline 21 & -2.63 & -3.50 & -2.27 & -3.50 & -3.04 & -5.00 & -2.98 & -5.00 & -2.63 & -3.50 & -2.41 & -3.50 & -3.04 & -5.00 & -3.04 & -5.00 \\
\hline 22 & 2.27 & 3.00 & 1.76 & 2.00 & 2.95 & 5.00 & 2.65 & 5.00 & 1.93 & 2.50 & 1.67 & 2.30 & 3.03 & 5.00 & 2.98 & 5.00 \\
\hline 23 & 2.50 & 3.50 & 1.69 & 2.00 & 2.86 & 5.00 & 2.47 & 5.00 & 2.22 & 2.90 & 2.04 & 2.80 & 3.04 & 5.00 & 3.03 & 5.00 \\
\hline 24 & -3.04 & -5.00 & -2.98 & -5.00 & -3.04 & -5.00 & -3.02 & -5.00 & -3.04 & -5.00 & -3.03 & -5.00 & -3.04 & -5.00 & -3.04 & -5.00 \\
\hline 25 & 1.53 & 3.50 & 0.34 & 0.00 & 1.80 & 5.00 & 0.47 & 5.00 & 1.79 & 3.15 & 1.23 & 1.30 & 2.17 & 5.00 & 1.78 & 5.00 \\
\hline 26 & -2.99 & -4.50 & -2.62 & -4.00 & -3.02 & -5.00 & -2.99 & -5.00 & -3.01 & -4.50 & -2.70 & -4.00 & -3.04 & -5.00 & -3.03 & -5.00 \\
\hline 27 & 0.89 & 3.00 & 0.32 & 1.00 & 1.11 & 5.00 & 0.51 & 5.00 & 1.62 & 2.20 & 1.15 & 1.35 & 2.82 & 5.00 & 2.50 & 5.00 \\
\hline 28 & 2.50 & 3.50 & 2.13 & 2.00 & 2.86 & 5.00 & 2.64 & 5.00 & 2.38 & 3.30 & 2.20 & 1.90 & 2.86 & 5.00 & 2.76 & 5.00 \\
\hline 29 & -2.27 & -3.00 & -1.84 & -2.00 & -2.95 & -5.00 & -2.79 & -5.00 & -2.04 & -2.70 & -1.80 & -2.15 & -3.01 & -5.00 & -2.99 & -5.00 \\
\hline 30 & -1.53 & -3.50 & -0.77 & -2.00 & -1.80 & -5.00 & -1.13 & -5.00 & -2.38 & -3.45 & -1.95 & -1.90 & -2.76 & -5.00 & -2.62 & -5.00 \\
\hline DA & $100 \%$ & $100 \%$ & $90 \%$ & $93 \%$ & $100 \%$ & $100 \%$ & $93 \%$ & $93 \%$ & $93 \%$ & $93 \%$ & $93 \%$ & $93 \%$ & $93 \%$ & $93 \%$ & $93 \%$ & $93 \%$ \\
\hline MAE & 1.49 & 0.62 & 2.07 & 1.58 & 1.16 & 1.33 & 1.60 & 1.73 & 1.59 & 1.09 & 1.82 & 1.38 & 1.17 & 1.73 & 1.22 & 1.73 \\
\hline RMSE & 1.66 & 0.89 & 2.26 & 1.86 & 1.38 & 1.53 & 1.95 & 2.52 & 1.85 & 1.65 & 2.00 & 1.72 & 1.67 & 2.52 & 1.66 & 2.52 \\
\hline
\end{tabular}

Note(s): GRey color indicates a conflict between tool and expert, and italic best performing setting 
support (Tate et al., 2014; Gray et al., 2017) and the existing research is very limited (Barbieri et al., 2018). The complexity arises from the large number of criteria that could be considered in the decision and the trade-offs between the criteria that must be balanced (Tate et al., 2014). Involving too many criteria could also increase the complexity and lead to prediction errors if there are uncertainties in the supporting data (Gray et al., 2017). In addition, the timing of manufacturing reshoring decisions is critical (Boffelli et al., 2018). For instance, firms do not want to have the decision-making process delayed until all the relevant criteria have been identified and the appropriate data on the criteria collected (Hartman et al., 2017) nor waste resources on evaluating wrong things for too long.

Even if the existing research argues for the need of more advanced decision-support tools in this domain (Hilletofth et al., 2019a), it does not provide an overview on the various kind of decision-support tools that are needed in order to support the decision-making process in an effective and efficient manner. Thus, this research has proposed an overarching classification of the various kinds of decision-support tools that are needed to support the entire decisionmaking process. The classification includes five kinds of decision-support tools each one linked to a particular phase in the decision-making process, including tools for feasibility evaluation, performance evaluation, scenario generation, scenario evaluation and scenario visualization. But above all, this research has developed two support tools for initial screening of manufacturing reshoring decisions that can be used for feasibility and/or initial scenario evaluation.

The developed support tools are capable of suggesting whether a reshoring decision should be further evaluated or not, based on six primary competitiveness criteria. The overall idea of the developed support tools is to identify the most promising projects and put efforts into those and not waste time on less promising projects. An initial screening tool could take departure from various sets of decision criteria including competitiveness, resource availability, and strategic orientation (Ancarani et al., 2015; Benstead et al., 2017) and be implemented on a primary-criteria or sub-criteria level (Hilletofth et al., 2019b). For the development of initial screening tools, competitiveness criteria on a primary-criteria level was considered to be the best starting point. The main argument is that this provides a holistic view on how to create competitiveness, which is the goal of all reshoring decisions. The relevance of the competitiveness criteria is also supported in the manufacturing reshoring literature (Benstead et al., 2017; Srai et al., 2016). The developed support tools also provide digital and automatic decision-support for decision makers and includes uncertainty, so that managers do not need to delay the process due to incomplete information (Boffelli et al., 2018; Hartman et al., 2017) or spend resources on opportunities that later turn out to be unfeasible. This means that the developed support tools help managers to invest their scarce time on the most promising reshoring projects and to make timely and resilient decisions by taking a holistic perspective on competitiveness. The developed support tools are knowledge-driven since they are based on expert knowledge. The reason for building knowledge-driven support tools is the lack of data on manufacturing reshoring projects.

The developed support tools were evaluated based on accuracy and interpretability. The tradeoff between accuracy and interpretability is well explored in the literature (Alcalá et al., 2006; Casillas et al., 2013) and the support tools were created to serve different aspects of this tradeoff. The design of the fuzzy rules within the developed support tools was based on recent fuzzy logic concepts (Hilletofth et al., 2019b). The first support tool aimed for high accuracy by using a complete rule base created through a semi-automatic approach (in total 729 rules) while the second support tool aimed for high interpretability by using a reduced rule base created through a high-level rules approach (in total 156 rules). The associated risk in the first support tool is reduced interpretability while the associated risk in the second support tool is reduced accuracy (Casillas et al., 2013; Mencar and Fanelli, 2008). 
IMDS

121,5

\section{4}

Table 6.

Average DA, MAE and RMSE for the tool and each fuzzy inference function

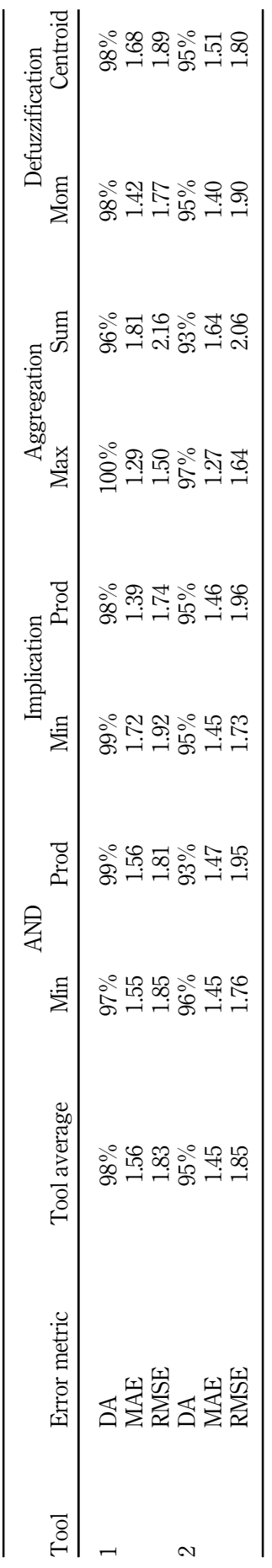


Fuzzy-logic-

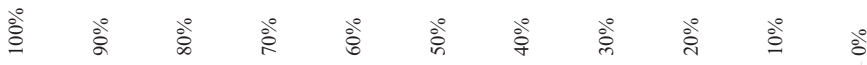

based support

tools
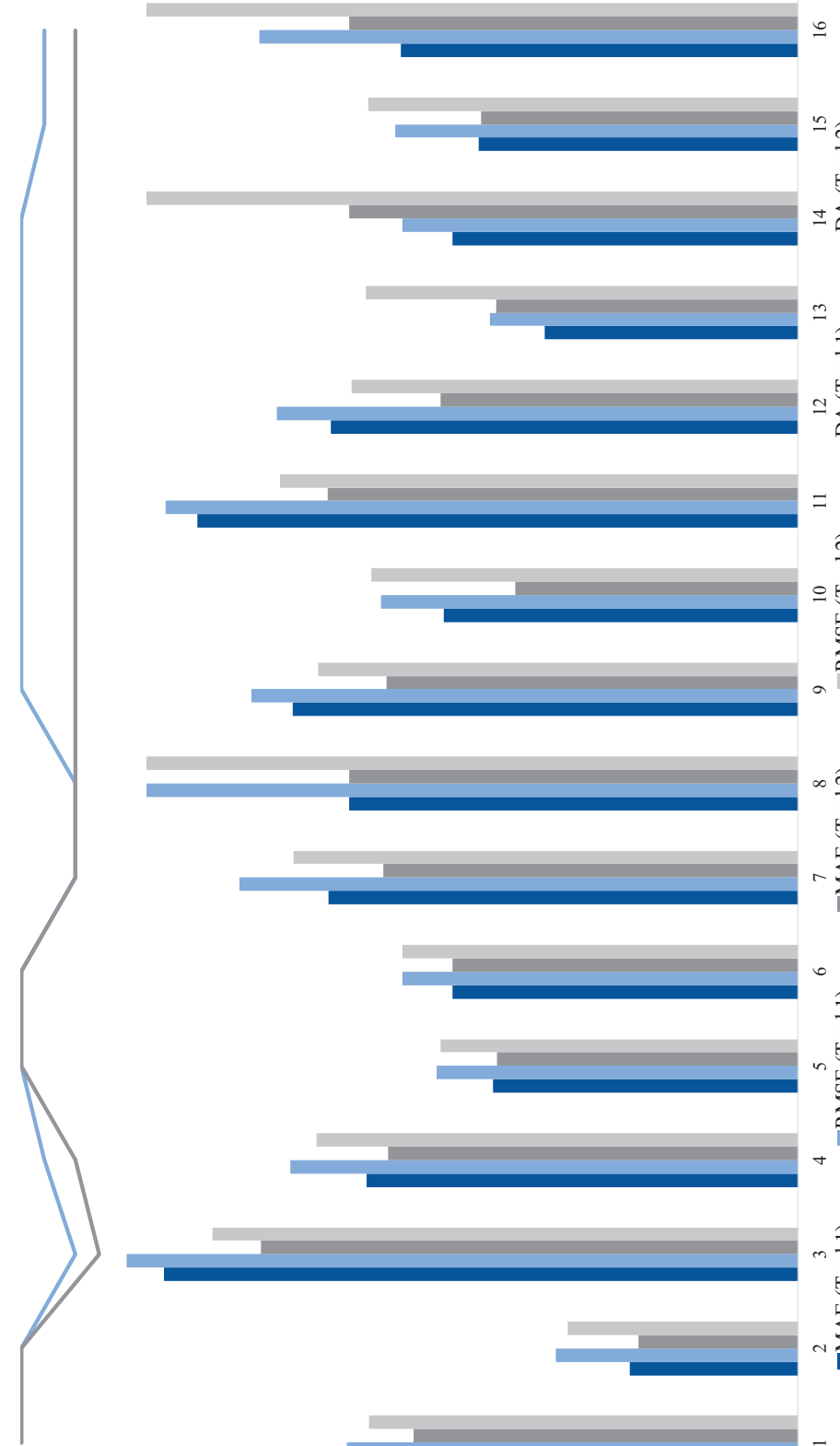

$\frac{1}{0}$

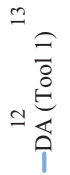

\section{$=$}

용

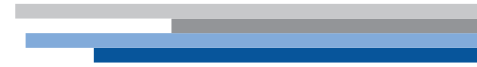

$ㄷ$

(x)

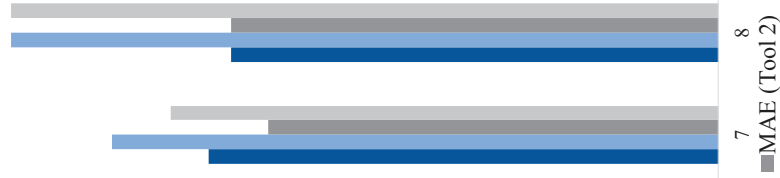

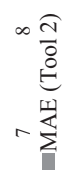

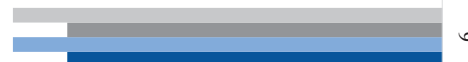

in
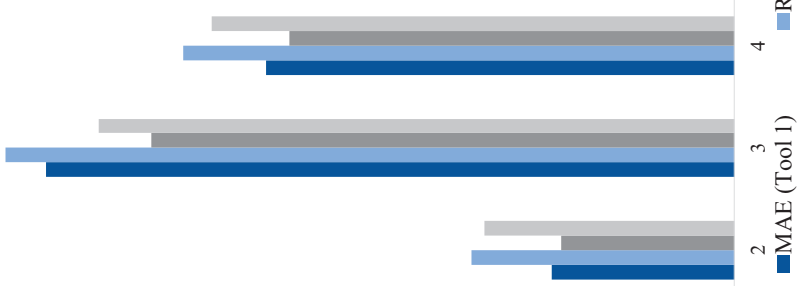

$\underbrace{\frac{\mathcal{I}}{8}}_{N}$

Figure 7.

Comparison of DA,

MAE and RMSE across settings in the developed

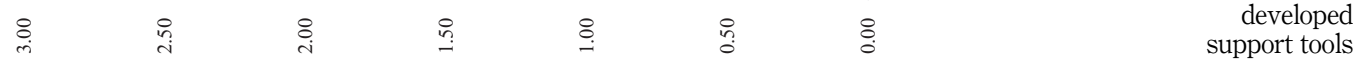


IMDS

121,5

The accuracy of the developed support systems was evaluated by comparing tool output with experts' opinion using three different error metrics (DA, MAE and RMSE), in accordance with previous studies (Hilletofth et al., 2019b; Syn et al., 2011). This was done on an individual settings level and on an overall tool level. For most of the scenarios and settings, there were no conflicts between tool output and experts' opinion. The first support tool made the same evaluation as the reshoring experts $98 \%$ of the time while the second support tool made the same evaluation $95 \%$ of the time. This level of agreement suggests that the developed support tools are able to approximate the reasoning of the involved reshoring experts. Similar levels of accuracy have been reported in previous studies (Muzaffar and Ahmed, 2010) and could be considered as high. The above means that the first support tool has higher DA than the second support tool and thus performs better. However, the MAE suggests that the second support tool performs better while the RMSE suggest the opposite. It is important to note that no statistically significant differences were found between the two developed tools. Hence, it can be concluded that it does not matter whether one uses a complete or reduced rule base when it comes to accuracy since the developed support tools perform similarly on an overall level.

The interpretability of the developed support tools was evaluated by comparing the overall tool design. Interestingly, the developed support tools perform similarly even if the used number of fuzzy rules differ significantly. The first tool uses 729 fuzzy rules while the second tool uses 156 fuzzy rules. The lower number of fuzzy rules used in the second support tool increases the interpretability (Zhou and Gan, 2008). A small set of high-level rules were proposed by the involved reshoring experts and these were translated into 156 fuzzy rules, making the overall design easier to interpret for decision-makers. Furthermore, the high-level rules also reduced the amount of time needed from both involved reshoring experts and the tool developer, when designing the fuzzy rules. This means that you achieve almost the same accuracy in a more convenient way. Hence, it can be concluded that a reduced rule base (i.e. the second support tool) is preferable for initial screening purposes since it uses fewer resources and is more interpretable, and still performs similarly. Whereas previous research has linked interpretability advantages to the high-level rules approach (Hilletofth et al., 2019b), this research also suggests that the approach has accuracy advantages. The two main reasons for why the usual accuracy-interpretability tradeoff is not present in this study could be that the second support tool relied on both a systematic application of high-level rules and a high level of expert involvement.

The choice of fuzzy inference settings in the developed support tools impact the overall tool performance, since the inference settings determine how the fuzzy rules are be executed (Syn et al., 2011). In total, sixteen fuzzy inference settings were used in both of the support tools by combining the most relevant AND, implication, aggregation and defuzzification functions. The results show that the different inference settings generated different DA, MAE and RMSE values, although one setting performed better than all the other settings in both support tools. In addition, the same settings performed worse in both of the developed support systems with some differences depending on whether MAE or RMSE is considered. The results from each fuzzy inference function show that among the two AND functions (i.e. Min or Prod), implication functions (i.e. Min or Prod) and the defuzzification functions (i.e. Mom or Centroid), there is no preferred function that works best for both support tools. However, for the aggregation method, maximum is the preferred aggregation function. These functions and settings have been shown to behave well for fuzzy logic tools in other domains as well (Syn et al., 2011). When comparing the individual settings, it is evident than one setting performs better than the others in both support tools. Hence, it can be concluded that it does not matter whether one uses a complete or reduced rule base performance wise. However, regardless whether a complete or reduced tool is used, it is important to select the right setting. 


\section{Conclusion and further research}

The aim of this study was to investigate the suitability of fuzzy-logic-based support tools for initial screening of manufacturing reshoring decisions. To achieve this, two fuzzy-logic-based support tools were developed together with experts from a Swedish manufacturing firm. The first support tool used a complete rule base, while the second used a reduced rule base. In both of the support tools, sixteen fuzzy inference settings were used. The research shows that fuzzy-logic-based support tools are suitable for initial screening of manufacturing reshoring decisions. The developed support tools are capable of suggesting whether a reshoring decision should be further evaluated or not, based on six primary competitiveness criteria. In contrast to existing literature, this research shows that it does not matter whether a complete or reduced rule base is used when it comes to performance. The developed support tools perform similarly with no statistically significant differences. However, since the interpretability is much higher when a reduced rule base is used and it requires fewer resources to develop, the second tool is more preferable for initial screening purposes. Regardless of whether a complete or reduced tool is used, it is important to select the right setting.

This research has implications for both research and practice. This research has addressed the issue of decision-support in the manufacturing reshoring domain, which is an issue where the existing research is very limited. This research proposed an overarching classification of the different types of decision-support tools that are needed to support the reshoring decision-making process. This research also has proposed support tools for initial screening of manufacturing reshoring decisions that can be used for feasibility and/or initial scenario evaluation. The overarching classification of decision support tools opens up plenty of avenues for development of tools to support the decision-making process in the future.

The developed support tools help managers to invest their scarce time on the most promising manufacturing reshoring projects and to make timely and resilient decisions by taking a holistic perspective on competitiveness. This research provides practitioners with advice on how to select overall tool design and how to configure the tool for best performance and interpretability. Practitioners are advised to develop initial screening tools that use a reduced rule base since they use fewer resources and are more interpretable, and still perform similarly to tools that uses a complete rule base. However, the choice is also linked to the availability of data. Easy access to complete and correct data encourages support tools that are based on a complete rule base. Another advice for practitioners is that it is more important to select the right setting than overall tool design.

As in all research, there are some limitations that should be addressed in future research. First, the developed support tools are implemented at a primary-criteria level and in order to make them more applicable, they should also include the sub-criteria level. This requires further knowledge on the reshoring sub-criteria and their interdependencies. The support tools should also be expanded to not only consider competitiveness criteria, but also other criteria related to availability of resources and strategic orientation of the firm. This calls for further research on how a multilevel architecture could be implemented and how fuzzy rules could be generated automatically in the manufacturing reshoring domain. Second, the membership functions were not optimized for individual settings in the developed tools. To further evaluate and compare different settings, different membership functions may be needed for each setting. Hence, further research is needed to investigate whether individual inference settings perform better with particular membership functions in the manufacturing reshoring domain. Third, the tools were developed for a specific empirical setting. The industrial context was manufacturing of transportation equipment in Sweden and it concerned partial reshoring for insourcing on a component level. The tools should be evaluated in other empirical settings to further validate the findings.
Fuzzy-logicbased support tools 
IMDS

121,5

\section{Note}

1. Results of two-sample $t$-test: No significant difference in MAE for the first support tool (Mean $=1.56$, Standard deviation $=0.4647$ ) and the second support tool (Mean $=1.45$, standard deviation $=0.3539)$, conditions $t(30)=0.688, p=0.497$. No significant difference in RMSE for the first support tool (Mean $=1.83$, Standard deviation $=0.478$ ) and the second support tool $($ Mean $=1.85, \mathrm{SD}=0.443)$, conditions $t(30)=-0.103, p=0.919$.

\section{8}

\section{References}

Alcalá, R., Alcalá-Fdez, J., Casillas, J., Cordón, O. and Herrera, F. (2006), "Hybrid learning models to get the interpretability-accuracy trade-off in fuzzy modeling", Soft Computing, Vol. 10 No. 9, pp. 717-734.

Ancarani, A., Di Mauro, C., Fratocchi, L., Orzes, G. and Sartor, M. (2015), "Prior to reshoring: a duration analysis of foreign manufacturing ventures", International Journal of Production Economics, Vol. 169, pp. 141-155.

Arlbjørn, J.S. and Mikkelsen, O.S. (2014), "Backshoring manufacturing - notes on an important but under-researched theme", Journal of Purchasing and Supply Management, Vol. 20 No. 1, pp. 60-62.

Bailey, D. and De Propris, L. (2014), "Manufacturing reshoring and its limits - the UK automotive case", Cambridge Journal of Regions, Economy and Society, Vol. 7 No. 3, pp. 379-395.

Bals, L., Kirchoff, J.F. and Foerstl, K. (2016), "Exploring the reshoring and insourcing decision making process: toward an agenda for future research", Operations Management Research, Vol. 9 Nos 3-4, pp. 102-116.

Baraldi, E., Ciabuschi, F., Fratocchi, L. and Lindahl, O. (2018), "A network perspective on the reshoring process: the relevance of the home- and the host-country contexts", Industrial Marketing Management, Vol. 70, pp. 156-166.

Barbieri, P., Ciabuschi, F., Fratocchi, L. and Vignoli, M. (2018), "What do we know about manufacturing reshoring?", Journal of Global Operations and Strategic Sourcing, Vol. 11 No. 1, pp. 79-122.

Benstead, A.V., Stevenson, M. and Hendry, L.C. (2017), "Why and how do firms reshore? A contingency-based conceptual framework", Operations Management Research, Vol. 10 Nos 3-4, pp. 85-103.

Boffelli, A., Orzes, G. and Dotti, S. (2018), "How to reshore': some evidence from the apparel industry", IEEE Engineering Management Review, Vol. 46 No. 4, pp. 122-127.

Brennan, L., Ferdows, K., Golini, R., Keegan, R., Kinkel, S., Srai, J.S. and Taylor, M. (2015), "Manufacturing in the world: where next?", International Journal of Operations and Production Management, Vol. 35 No. 9, pp. 1253-1274.

Casillas, J., Cordón, O., Triguero, F.H. and Magdalena, L. (Eds) (2013), Interpretability Issues in Fuzzy Modeling, Springer Verlag, Berlin, Vol. 128.

Castro, J.L. and Delgado, M. (1996), "Fuzzy systems with defuzzification are universal approximators", IEEE Transactions on Systems, Man, and Cybernetics, Part B (Cybernetics), Vol. 26 No. 1, pp. 149-152.

Chen, T., Shen, Q., Su, P. and Shang, C. (2016), "Fuzzy rule weight modification with particle swarm optimisation”, Soft Computing, Vol. 20 No. 8, pp. 2923-2937.

Cordón, O. (2011), "A historical review of evolutionary learning methods for Mamdani-type fuzzy rulebased systems: designing interpretable genetic fuzzy systems", International Journal of Approximate Reasoning, Vol. 52 No. 6, pp. 894-913.

Cordón, O. and Herrera, F. (2000), "A proposal for improving the accuracy of linguistic modeling”, IEEE Transactions on Fuzzy Systems, Vol. 8 No. 3, pp. 335-344.

Cpałka, K. (2017), Design of Interpretable Fuzzy Systems, Springer International Publishing, Cham. 
Di Mauro, C., Fratocchi, L., Orzes, G. and Sartor, M. (2018), "Offshoring and backshoring - a multiple case study analysis", Journal of Purchasing and Supply Management, Vol. 24 No. 2, pp. 108-134.

Dunning, J.H. (1980), "Toward an eclectic theory of international production: some empirical tests", Journal of International Business Studies, Vol. 11 No. 1, pp. 9-31.

Duţu, L.C., Mauris, G. and Bolon, P. (2018), "A fast and accurate rule base generation method for Mamdani fuzzy systems”, IEEE Transactions on Fuzzy Systems, Vol. 26 No. 2, pp. 715-733.

Ellram, L.M., Tate, W.L. and Petersen, K.J. (2013), "Offshoring and reshoring - an update on the manufacturing location decision”, Journal of Supply Chain Management, Vol. 49 No. 2, pp. 14-22.

Engström, G., Hilletofth, P., Eriksson, D. and Sollander, K. (2018a), "Drivers and barriers of reshoring in the Swedish manufacturing industry", World Review of Intermodal Transportation Research, Vol. 7 No. 3, pp. 195-220.

Engström, G., Sollander, K., Hilletofth, P. and Eriksson, D. (2018b), "Reshoring drivers and barriers in the Swedish manufacturing industry", Journal of Global Operations and Strategic Sourcing, Vol. 11 No. 2, pp. 174-201.

Eriksson, D., Hilletofth, P., Ellram, L.M. and Sansone, C. (2018), "To offshore or reshore - the battle of data points", Supply Chain Management Review, Vol. 22 No. 3, pp. 42-46.

Esogbue, A.O. and Song, Q. (2003), "On optimal defuzzification and learning algorithms: theory and applications", Fuzzy Optimization and Decision Making, Vol. 2 No. 4, pp. 283-296.

Foerstl, K., Kirchoff, J.F. and Bals, L. (2016), "Reshoring and insourcing: drivers and future research directions", International Journal of Physical Distribution and Logistics Management, Vol. 46 No. 5, pp. 492-515.

Fratocchi, L., Di Mauro, C., Barbieri, P., Nassimbeni, G. and Zanoni, A. (2014), "When manufacturing moves back: concepts and questions", Journal of Purchasing and Supply Management, Vol. 20 No. 1, pp. 54-59.

Fratocchi, L., Ancarani, A., Barbieri, P., Di Mauro, C., Nassimbeni, G., Sartor, M. and Zanoni, A. (2016), "Motivations of manufacturing reshoring: an interpretative framework", International Journal of Physical Distribution and Logistics Management, Vol. 46 No. 2, pp. 98-127.

Gacto, M.J., Alcalá, R. and Herrera, F. (2011), "Interpretability of linguistic fuzzy rule-based systems: an overview of interpretability measures", Information Sciences, Vol. 181 No. 20, pp. 4340-4360.

Gegov, A., Sanders, D. and Vatchova, B. (2017), "Aggregation of inconsistent rules for fuzzy rule base simplification", International Journal of Knowledge-Based and Intelligent Engineering Systems, Vol. 21 No. 3, pp. 135-145.

Govindan, K., Mina, H. and Alavi, B. (2020), "A decision support system for demand management in healthcare supply chains considering the epidemic outbreaks: a case study of coronavirus disease 2019 (COVID-19)", Transportation Research Part E: Logistics and Transportation Review, Vol. 138, p. 101967.

Gray, J.V., Skowronski, K., Esenduran, G. and Rungtusanatham, M. (2013), "The reshoring phenomenon - what supply chain academics ought to know and should do", Journal of Supply Chain Management, Vol. 49 No. 2, pp. 27-33.

Gray, J.V., Esenduran, G., Rungtusanatham, M.J. and Skowronski, K. (2017), "Why in the world did they reshore? Examining small to medium-sized manufacturer decisions", Journal of Operations Management, Vol. 49, pp. 37-51.

Gylling, M., Heikkilä, J., Jussila, K. and Saarinen, M. (2015), "Making decisions on offshore outsourcing and backshoring: a case study in the bicycle industry", International Journal of Production Economics, Vol. 162, pp. 92-100.

Hartman, P.L., Ogden, J.A., Wirthlin, J.R. and Hazen, B.T. (2017), "Nearshoring, reshoring, and insourcing: moving beyond the total cost of ownership conversation", Business Horizons, Vol. 60 No. 3, pp. 363-373.
Fuzzy-logicbased support tools 
IMDS 121,5

Heikkilä, J., Martinsuo, M. and Nenonen, S. (2018), "Backshoring of production in the context of a small and open Nordic economy", Journal of Manufacturing Technology Management, Vol. 29 No. 4, pp. 658-675.

Hilletofth, P., Hilmola, O.-P. and Wang, Y. (2016), "Simulation based decision support systems in the supply chain context”, Industrial Management and Data Systems, Vol. 116 No. 2.

Hilletofth, P., Eriksson, D., Tate, W. and Kinkel, S. (2019a), "Right-shoring: making resilient offshoring and reshoring decisions", Journal of Purchasing and Supply Management, Vol. 25 No. 3, p. 100540.

Hilletofth, P., Sequeira, M. and Adlemo, A. (2019b), "Three novel fuzzy logic concepts applied to reshoring decision making”, Expert System with Applications, Vol. 126, pp. 133-143.

Johansson, M. and Olhager, J. (2018), "Manufacturing relocation through offshoring and backshoring the case of Sweden", Journal of Manufacturing Technology Management, Vol. 29 No. 4, pp. 637-657.

Joubioux, C. and Vanpoucke, E. (2016), "Towards right-shoring: a framework for off-and re-shoring decision making", Operations Management Research, Vol. 9 Nos 3-4, pp. 117-132.

Ketokivi, M., Turkulainen, V., Seppala, T., Rouvinen, P. and Ali-Yrkkö, J. (2017), "Why locating manufacturing in a high-cost country? A case study of 35 production location decisions", Journal of Operations Management, Vol. 49, pp. 20-30.

Lee, C.C. (1990), "Fuzzy logic in control systems: fuzzy logic controller. II", IEEE Transactions on Systems, Man, and Cybernetics, Vol. 20 No. 2, pp. 419-435.

Leo Kumar, S.P. (2019), "Knowledge-based expert system in manufacturing planning: state-of-the-art review", International Journal of Production Research, Vol. 57 Nos 15-16, pp. 4766-4790.

Liao, S.H. (2005), "Expert system methodologies and applications-a decade review from 1995 to 2004”, Expert Systems with Applications, Vol. 28 No. 1, pp. 93-103.

Martínez-Mora, C. and Merino, F. (2014), "Offshoring in the Spanish footwear industry: a return journey?”, Journal of Purchasing and Supply Management, Vol. 20 No. 4, pp. 225-237.

MATLAB (2018), Version 9.5.0 (R2018a), The MathWorks, Natick, MA.

Mencar, C. and Fanelli, A.M. (2008), "Interpretability constraints for fuzzy information granulation", Information Sciences, Vol. 178 No. 24, pp. 4585-4618.

Morente-Molinera, J.A., Kou, G., González-Crespo, R., Corchado, J.M. and Herrera-Viedma, E. (2017), "Solving multi-criteria group decision making problems under environments with a high number of alternatives using fuzzy ontologies and multi-granular linguistic modelling methods", Knowledge-Based Systems, Vol. 137, pp. 54-64.

Muzaffar, Z. and Ahmed, M.A. (2010), "Software development effort prediction: a study on the factors impacting the accuracy of fuzzy logic systems", Information and Software Technology, Vol. 52 No. 1, pp. 92-109.

Nunes, I. and Jannach, D. (2017), "A systematic review and taxonomy of explanations in decision support and recommender systems", User Modeling and User-Adapted Interaction, Vol. 27 Nos 3-5, pp. 393-444.

Panova, Y. and Hilletofth, P. (2017), "Feasibility of nearshoring European manufacturing located in China to Russia”, Operations and Supply Chain Management, Vol. 10 No. 3, pp. 141-148.

Power, D.J. (2008), "Decision support systems: a historical overview", Handbook on Decision Support Systems, Springer, Berlin, Heidelberg, Vol. 1, pp. 121-140.

Ross, T.J. (2017), Fuzzy Logic with Engineering Applications, Wiley, Sussex.

Sadati, N., Chinnam, R.B. and Nezhad, M.Z. (2018), "Observational data-driven modeling and optimization of manufacturing processes", Expert Systems with Applications, Vol. 93, pp. 456-464.

Sadjadi, E.N., Herrero, J.G., Molina, J.M. and Moghaddam, Z.H. (2018), "On approximation properties of smooth fuzzy models”, International Journal of Fuzzy Systems, Vol. 20 No. 8, pp. 2657-2667. 
Sambariya, D.K. and Prasad, R. (2017), "Selection of membership functions based on fuzzy rules to design an efficient power system stabilizer", International Journal of Fuzzy Systems, Vol. 19 No. 3, pp. 813-828.

Sansone, C., Hilletofth, P. and Eriksson, D. (2017), "Critical operations capabilities for competitive manufacturing - a systematic review", Industrial Management and Data Systems, Vol. 117 No. 5, pp. 801-837.

Sansone, C., Hilletofth, P. and Eriksson, D. (2020), "Critical operations capabilities for competitive manufacturing in a high-cost environment: a multiple case study", Operations and Supply Chain Management: International Journal, Vol. 13 No. 1, pp. 96-109.

Shaout, A. and Trivedi, J. (2013), "Performance appraisal system using a multistage fuzzy architecture", International Journal of Computer and Information Technology, Vol. 2 No. 3, pp. 405-411.

Shukla, P.K. and Tripathi, S.P. (2012), "A review on the interpretability-accuracy trade-off in evolutionary multi-objective fuzzy systems (EMOFS)", Information, Vol. 3 No. 3, pp. 256-277.

Srai, J.S. and Ané, C. (2016), "Institutional and strategic operations perspectives on manufacturing reshoring”, International Journal of Production Research, Vol. 54 No. 23, pp. 7193-7211.

Stentoft, J., Mikkelsen, O.S. and Johnsen, T.E. (2015), "Going local - a trend towards insourcing of production?”, Supply Chain Forum: International Journal, Vol. 16 No. 1, pp. 2-13.

Stentoft, J., Olhager, J., Heikkilä, J. and Thoms, L. (2016), "Manufacturing backshoring: a systematic literature review", Operations Management Research, Vol. 9 Nos 3-4, pp. 53-61.

Syn, C.Z., Mokhtar, M., Feng, C.J. and Manurung, Y.H. (2011), “Approach to prediction of laser cutting quality by employing fuzzy expert system”, Expert Systems with Applications, Vol. 38 No. 6, pp. 7558-7568.

Talon, A. and Curt, C. (2017), "Selection of appropriate defuzzification methods: application to the assessment of dam performance”, Expert Systems with Applications, Vol. 70, pp. 160-174.

Tan, Y., Shum, H.P., Chao, F., Vijayakumar, V. and Yang, L. (2019), "Curvature-based sparse rule base generation for fuzzy rule interpolation", Journal of Intelligent and Fuzzy Systems, Vol. 36 No 5, pp. 4201-4214.

Tate, W.L., Ellram, L.M., Schoenherr, T. and Petersen, K.J. (2014), "Global competitive conditions driving the manufacturing location decision”, Business Horizons, Vol. 57 No. 3, pp. 381-390.

Vanchan, V., Mulhall, R. and Bryson, J. (2018), "Repatriation or reshoring of manufacturing to the US and UK: dynamics and global production networks or from here to there and back again", Growth and Change, Vol. 49 No. 1, pp. 97-121.

Wiesmann, B., Snoei, J.R., Hilletofth, P. and Eriksson, D. (2017), "Drivers and barriers to reshoring - a literature review on offshoring in reverse", European Business Review, Vol. 29 No. 1, pp. 15-42.

Yazdanbakhsh, O. and Dick, S. (2018), "A systematic review of complex fuzzy sets and logic”, Fuzzy Sets and Systems, Vol. 338, pp. 1-22.

Zadeh, L.A. (1965), "Fuzzy sets”, Information and Control, Vol. 8 No. 3, pp. 338-353.

Zhou, S.M. and Gan, J.Q. (2008), "Low-level interpretability and high-level interpretability - a unified view of data-driven interpretable fuzzy system modelling”, Fuzzy Sets and Systems, Vol. 159 No. 23, pp. 3091-3131.

\section{About the authors}

Per Hilletofth is a Professor of Industrial Management at University of Gävle in Sweden. His research focuses on operations strategy, manufacturing location, supply chain design, new product development, and demand and supply integration. He has published articles in international journals including Supply Chain Management: an international journal, Production Planning and Control, Expert Systems with Applications, Industrial Management and Data Systems, Journal of Business and Industrial Marketing, Innovation: Organization and Management, Journal of Manufacturing Technology Management, and 
IMDS

121,5

992
European Business Review. He has editorial assignments in several international journals. Per Hilletofth is the corresponding author and can be contacted at: prof.p.hilletofth@gmail.com

Movin Sequeira (MSc) is a PhD Student at Jönköping University in Sweden. His research interest includes manufacturing relocation and sustainable production. He has an M.Sc. degree in Production Development and Management from Jönköping University.

Wendy Tate, Ph.D. (Arizona State University 2006) is a Professor of Supply Chain Management in the Department of Supply Chain Management at the University of Tennessee. She teaches undergraduate, MBA, PhD, and executive education students Strategic Sourcing. She has an interest in the financial impacts of business decisions (and supply chain finance) across the supply chain. Her research focuses on two primary business problems. The first is in the area of services purchasing including outsourcing and offshoring. The second is on sustainability initiatives and trying to understand how these can be diffused across a supply chain and a supply network.

For instructions on how to order reprints of this article, please visit our website: 